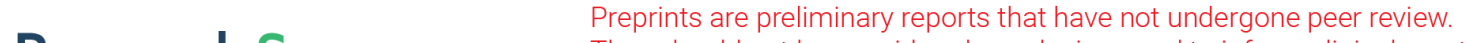 \\ They should not be considered conclusive, used to inform clinical practice, \\ or referenced by the media as validated information. \\ Design of Honeycomb Shaped Spectroscopy based Biosensor for the Detection of Tuberculosis Cells
}

\section{Tarunnum Parvin}

National Institute of Technology Patna

\section{S Zobaer}

The University of Texas Health Science Center at Houston

\section{Kawsar Ahmed}

Mawlana Bhashani Science and Technology University

\section{Francis Minhthang Bui}

University of Saskatchewan

\section{Sumaiya Akhtar Mitu}

Mawlana Bhashani Science and Technology University

\section{Vigneswaran}

Anna University Chennai

Murugan senthil Mani rajan ( $\nabla$ senthilmanirajanofc@gmail.com )

ANNA UNIVERSITY CHENNAI https://orcid.org/0000-0003-0562-2469

\section{Research Article}

Keywords: Honeycomb, Tuberculosis Cells, Biosensor

Posted Date: June 2nd, 2021

DOI: https://doi.org/10.21203/rs.3.rs-542970/v1

License: (c) (1) This work is licensed under a Creative Commons Attribution 4.0 International License.

Read Full License 


\title{
Design of Honeycomb Shaped Spectroscopy based Biosensor for the Detection of Tuberculosis Cells
}

\author{
Tarunnum Parvin ${ }^{1}$, M S Zobaer ${ }^{2}$, Kawsar Ahmed ${ }^{3}$, Francis Minhthang Bui ${ }^{4}$, Sumaiya Akhtar Mitu, D. \\ Vigneswaran ${ }^{5}$, M.S. Mani Rajan ${ }^{5 *}$ \\ ${ }^{1}$ Department of Electronics and Communication Engineering, National Institute of Technology, Patna, \\ Bihar 800005, India \\ ${ }^{2}$ McGovern Medical School, The University of Texas Health Science Center at Houston TX 77030, \\ USA. \\ ${ }^{3}$ Group of Biophotomatix, Department of Information and Communication Technology (ICT), Mawlana \\ Bhashani Science and Technology University (MBSTU), Tangail 1902, Bangladesh \\ ${ }^{4}$ Department of Electrical and Computer Engineering, University of Saskatchewan, 57 Campus Drive, \\ Saskatoon, SK S7N 5A9, Canada \\ ${ }^{5}$ Department of Physics, University College of Engineering, Ramanathapuram campus, Tamil Nadu, \\ India
}

\begin{abstract}
A novel compact honeycomb spectroscopic-based PCF sensor for the detection of tuberculosis cells is proposed. A circular shape core area and tightly bound hexagonal shape air holes in the cladding area are designed for the suggested structure that exhibits ultra-high sensitivity up to $99.99 \%$ and very low loss of order $10^{-11} \mathrm{~dB} / \mathrm{m}$. The optical parameters such as effective area (A $\left.A_{\text {eff }}\right), V$-parameter or normalized frequency $\left(\mathrm{V}_{\text {eff }}\right)$, spot- size $\left(\mathrm{W}_{\text {eff }}\right)$, numerical aperture, along quality factor of beam have been exhibited and numerically observed. The wavelength operating region is specified as $1.2 \mu \mathrm{m}$ to $2.5 \mu \mathrm{m}$. The guiding properties of this suggested tuberculosis sensor is computed with the full vector finite element method (FV-FEM) in the environment of COMSOL Multiphysics (Version5.3) for the calculation of numerical analysis. Circular shape perfectly matched layer (PML) and hexagonal lattice PCF sensor using silica as a background material is successfully designed to increase the sensitivity response compare to the prior works. Moreover, during the entire operating wavelength presented sensor achieves a single mo-
\end{abstract}


dality. With excellent sensitivity response and very low confinement loss, this proposed sensor doubtfully proves its prominent role to detect tuberculosis cells.

\section{Introduction}

The tremendous application and potentiality of PCF can be shown in the sensing application. Due to design flexibility, PCF is always a core point of interest for the scientist. Several advantages can be shown of PCF over conventional fiber. Due to low confinement loss [1], high birefringent [2], high nonlinearity [3], the PCF is prominent. In this modern time, the PCF is the revolution due to lots of applications in the sensing area with additional advantages of less computational time, low cost, and better result. For measuring temperature[4], hydrostatic pressure [5], salinity sensor [6], gas sensor [7], detection of blood component refractive index [8], chemical sensing [9]detection of harmful additives in foods [10], PCF makes drastic changes in the field of sense due to powerful light-matter interaction property. Tuberculosis is a very common and deadly disease spreading due to mycobacterium tuberculosis. Observing the current data the number of people infected with TB (full form) is almost is one-third of the third of the total population. It is examined that every minute five death are caused due to tuberculosis. Most lungs of a person are being infected with this deadly disease. A person infected with these diseases when sneezes, the bacteria is spread into the air and that is the reason for spreading these dangerous and harmful diseases [11]. The characteristics shown by tuberculosis bacteria are that they can remain inactive for a long time without harming a person but as soon as the person becomes weak the TB bacteria become active and start to affect the lungs also other parts of the body. Other illness also aggravates these painful diseases like HIV that weeks the immune system. It is really painful that these deadly diseases are mostly in resource-poor countries and very limited success is achieved to detect and cure this disease [12]. The most unfortunate part of TB is that insufficient solutions for prevention and treatment. WHO (World Health Organization) started a plan for ending a disease named tuberculosis. The main purpose of this scheme is to reduce the number of patients earlier to 2025 and ending before 2035 [13]. The traditional methods for diagnosing and detecting TB are a long performing time and costly. These methods are chest radiology, culturing of the swab, manteaux test, and bacterioscopy [14]. One of the techniques known as specific DNA sequence amplification, it is used for the detection of mycobacterial by polymer chain reaction [15]. Chances of wrong results can be created because of amplified DNA infection. Also, this method is expensive due to the requirement of an experienced person and costly testing devices and it is also time-consuming [16]. In developing nations fluorography is not available always. To overcome these complications makes it essential of launching a new strong technique with high sensitivity, rapid 
detection time, effective in cost, and easier to handle. Due to flexibility of design, PCF is always a core point of interest for researchers.

Over the last decade due to great potentiality scientists are developing optical biosensors for detecting microorganism cells for detection of various diseases with less consuming time, rapid and cost-effective. And also it makes a revolution in the field of sensing by implementing various types of sensors. Different techniques of photonic crystal fiber like SPR (full form) [17] based, spectroscopic based [18] are extensively used due to tremendous sensing properties with excellent characteristics, easy to handle, simple in design with compact size makes these sensor unique one. Among all of the sensors, PCF-based fibers are acquiring more attention for disease detection, due to outstanding performances. In 2014, Hsu et al. demonstrated SPR based PCF by using telecommunication wavelength to detect Mycobacterium Tuberculosis (MTB) deoxyribonucleic acid (DNA). The sensitivity is enhanced with the increasing of wavelengths. But still, design complexity is here [19]. In 2017, M. Trzaskowski et al. designed compact SPR apparatus. It can detect Ag85 (Mycobacterium tuberculosis) secretory protein in the amount of 10 $\mathrm{mg} / \mathrm{ml}$ concentration that has limitations of concentrations [14]. In 2020, N.R. Ramanujam et al. proposed SPR based ring mirror-based defective PCF for detecting tuberculosis cells. The waveguide was examined by applying the well-known method TMM; i.e., Transfer Matrix Method. But, this method has also some complexity [11].

Various designs have already been demonstrated and investigated based on absorption spectroscopy. The first time the spectroscopic-based PCF sensor is presented with a unique honeycomb structure for detection of tuberculosis cells. Moreover, a large number of optical parameters are tuned for getting the better responses. As a result, high sensitivity response up to $99 \%$ with low confinement loss of order $10^{-}$

${ }^{8} \mathrm{~dB} / \mathrm{cm}$ is noted from the investigated structure. Besides, the sensor represents better outcomes as single modality, and good beam quality. From the obtained analysis it can be estimated that the proposed sensor will fit for the area of sensing technology as well as bio-technology.

\section{Design Methodology and Mode field Distributions}

The honeycomb photonic crystal fiber-based SPR sensor was previously designed for the detection of changes the refractive index of analyte. These Honeycomb designed structures, make as the similar design of bee honeycombs, has a wide range of applications in the fields of architecture, mechanical engi- 
neering, transportation, nanofabrication and, and biomedicine [20]. Inspiring from the previous discussions, a new designed honeycomb structure is proposed for the detection of tuberculosis cells.

Fig. 1 shows the cross-sectional view of the honeycomb suggested PCF structure. Silica is taken here as a background material. This unique structure of circular shape air holes core- region surrounded with hexagonal shape air holes makes it unique natural strongest shape. This tightly bound structure allows maximum light to confine with less amount of light is reflected. The diameter value of core air holes is taken $2.3 \mu \mathrm{m}$ and the pitch value is taken $2.6 \mu \mathrm{m}$. The Refractive index of silica is chosen by applying Sellmeier's formula [23,45]. The presented honeycomb structure has been examined for the wavelength region taken $1.2 \mu \mathrm{m}-2.5 \mu \mathrm{m}$. The main objective is to demonstrate a sensor with ultra-high sensitivity, lower confinement loss, and superior beam quality. The presented honeycomb structure is chosen in the cladding region due to high sensitivity for more light-matter interaction with very low order of confinement loss. The combined structure of circular shape air holes in the core area with hexagonal shape in the cladding area provides unique characteristics.

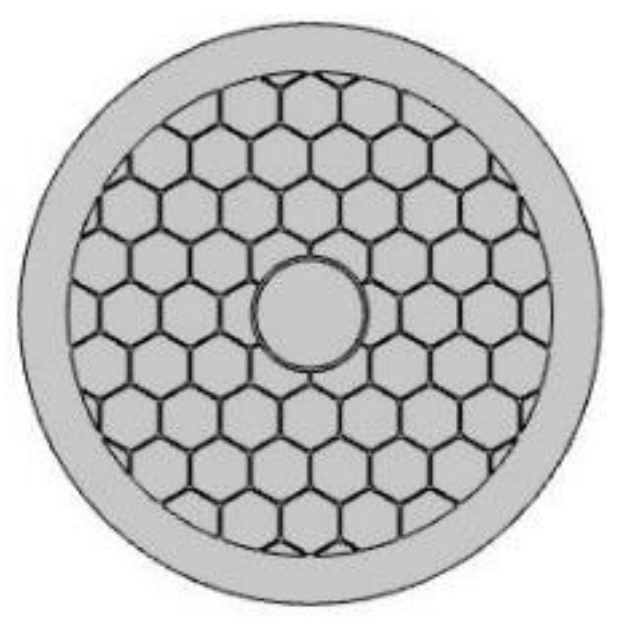

Fig. 1. The proposed tuberculosis sensor design by indicating analyte region

Background material for PCF also plays a vital role in obtaining good optical properties. Highly utilized material as the background is none other than silica due to lots of characteristics. Providing good resistance to noise and large bandwidth with higher sensitivity over wide wavelength silica has already proved its high utilization in PCF [21]. In the circular hole of the core region, refractive indices of tuberculosis cells are considered and many characteristics such as relative sensitivity, effective area (EA), numerical aperture (NA), confinement loss (CL), divergence parameter are investigated over a wavelength of $1.2 \mu \mathrm{m}$ to $2.4 \mu \mathrm{m}$. Distance between two adjacent air holes center is 
called pitch. The symbolic notation of pitch is $\Lambda$. Besides, one very important optical geometric parameter is known as air filling fraction (AFF). It is the ratio of $\mathrm{D}$ (diameter) and $\Lambda$ (pitch). AFF

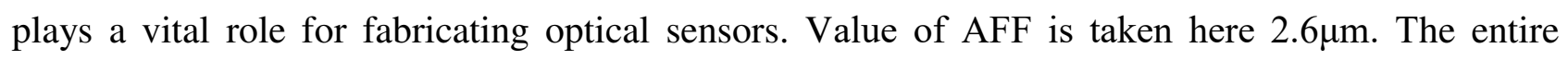
frame is bounded by circular shape boundary specified by perfectly matched layer. Incident electromotive force (EMF) waves are absorbed by PML without generating undesirable reflection. PML width is considered $10 \%$ of the radius of the cladding to avoid unwanted reflection. Fig. 2 shows the E-field distribution in both directions of the proposed fiber.

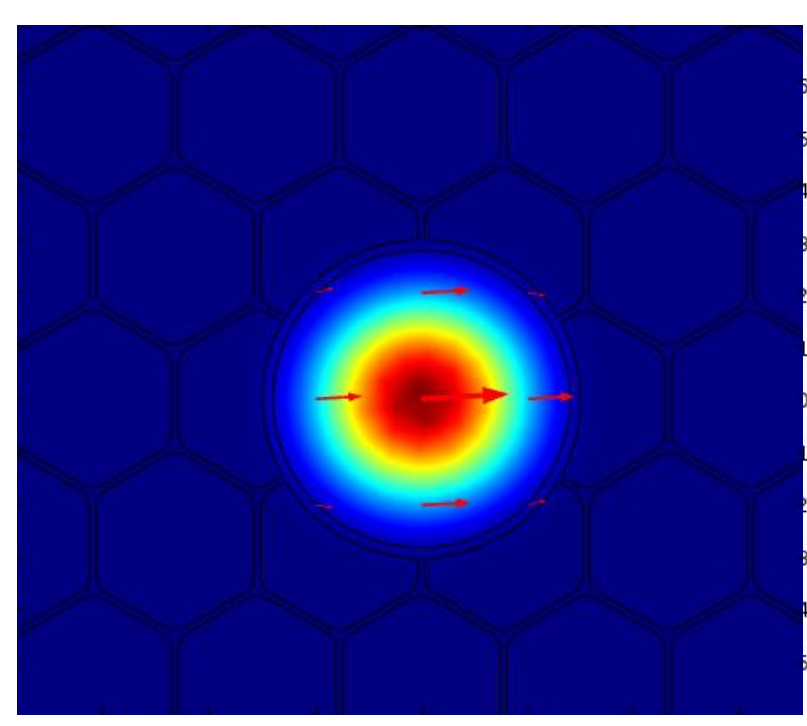

(a)

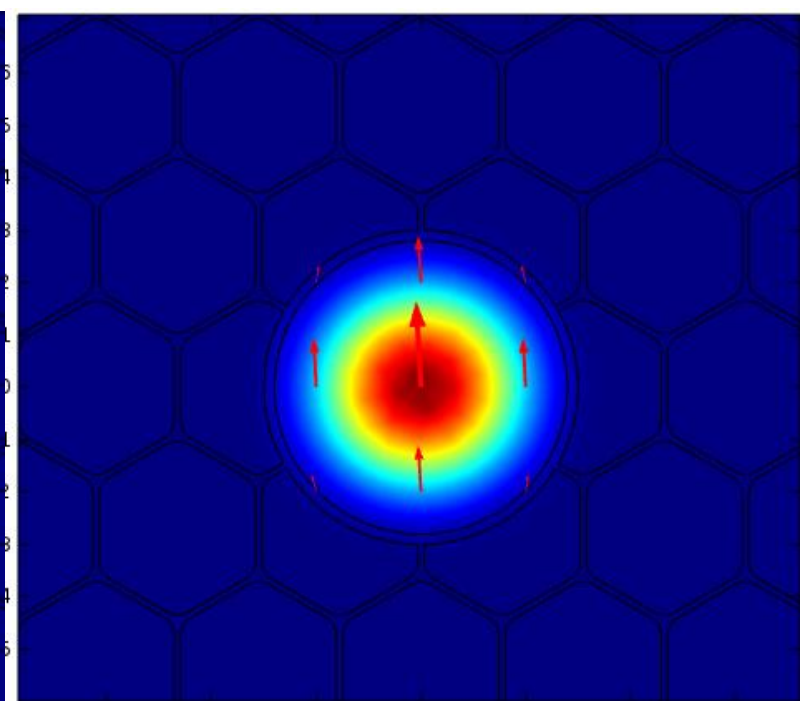

(b)

Fig. 2. Fundamental mode intensity distribution of presented sensor in both (a) X-polarization (b) Y-polarization

As the proposed sensor is a single mode fiber sensor, so the core mode of the fiber structure can be obtained for the two polarization modes [22]. The arrow sign indicates the direction of the polarizations. From Fig. 2, it is noted that the light intensity is maximum at the center of the core point. This type of light confining indicates the code mode of low loss value.

\section{Guiding properties of tuberculosis sensor}

Fig. 1shows the suggested spectroscopy-based structure of the tuberculosis sensor for rapid detection of several types of tuberculosis cells with fixed values of refractive index (RI). The variations of the RI of the selected tuberculosis cells are very low order of $10^{-4}$ in the operating wavelength. But the RI of background material, silica, was considered by applying Sellmeier's equation [23] 


$$
\mathrm{n}^{2}-1=\sum_{\mathrm{x}}^{3} \frac{\mathrm{A}_{\mathrm{x}} \times \lambda^{2}}{\lambda^{2}-\lambda_{\mathrm{x}}^{2}}
$$

In the following Eqn. (1), $\mathrm{n}$ is the notation as refractive index for indicated wavelength $\lambda(\mu \mathrm{m}) . \mathrm{A}_{\mathrm{x}}$ and $\lambda_{\mathrm{x}}$ are different parameters. The constant values of the parameters are exhibited in Table. 1.

Table. 1. The constant values of the parameters of Sellmier equation

\begin{tabular}{|l|l|l|l|}
\hline Parameter $\left(A_{x}\right)$ & Values & Parameter $\left(\lambda_{x}\right)$ & Values \\
\hline$A_{1}$ & 0.69616630 & $\lambda_{1}$ & 0.06840430 \\
\hline$A_{2}$ & 0.40794260 & $\lambda_{2}$ & 0.11624140 \\
\hline$A_{3}$ & 0.89747940 & $\lambda_{3}$ & 9.8961610 \\
\hline
\end{tabular}

\subsection{SENSITIVITY PROFILE}

The coefficient of relative sensitivity gives a perfect view of the interaction of light with directed material. Sensing response is realized for the proposed honeycomb PCF by calculating relative sensitivity. The following equation is used to measure the numerical value [24].

$$
r=\left(\frac{n_{r}}{R_{e}\left[n_{e f f}\right]}\right) t
$$

The index of refraction for the sample taken is $\mathrm{n}_{\mathrm{r}}$, which is taken 1.345 to 1.349 for tuberculosis cells and $\mathrm{n}_{\mathrm{eff}}$ is the notation here for guided mode effective refractive index at that particular wavelength, $\mathrm{r}$ is the denoted here relative sensitivity, $t$ is the amount of light that interacts with the analytic i.e. the percentage ratio $(\%)$ of the core power and total power. In the spectroscopy method, the $\mathrm{t}$ can be calculated by applying the pointing theorem. The power fraction can be evaluated by following expression (3) [2526].

$$
\mathrm{t}=\frac{\int_{\text {sample }} \mathrm{R}_{e}\left(\mathrm{E}_{\mathrm{x}} \mathrm{H}_{\mathrm{y}}-\mathrm{E}_{\mathrm{y}} \mathrm{H}_{\mathrm{x}}\right) \mathrm{dxdy}}{\int_{\text {whole }} \mathrm{R}_{\mathrm{e}}\left(\mathrm{E}_{\mathrm{x}} \mathrm{H}_{\mathrm{y}}-\mathrm{E}_{\mathrm{y}} \mathrm{H}_{\mathrm{x}}\right) \mathrm{dxdy}}
$$


In expression (3) the numerator portion is proficient for the tuberculosis cells sensed in the core-region. Here, in formula $E_{x}, E_{y}$ and $H_{x}, H_{y}$ notifies electric field components and magnetic field components of the guiding modes respective order shows the relative sensitivity of the proposed sensor.

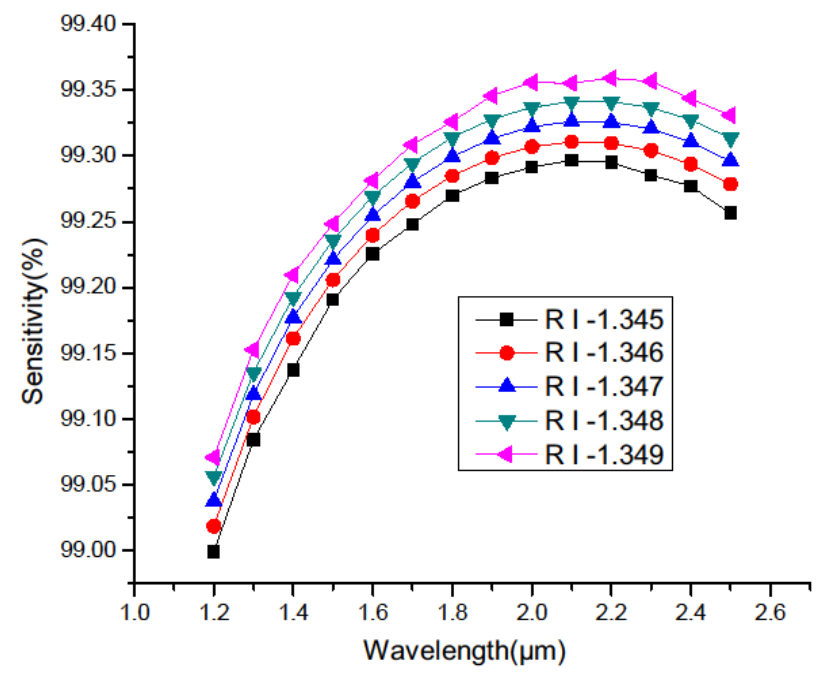

a)

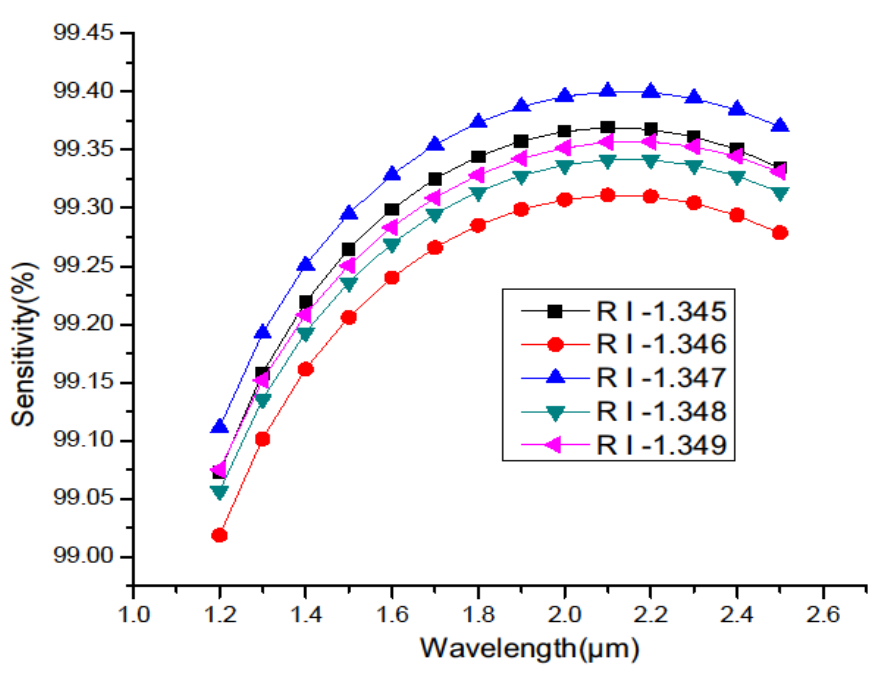

(b)

Fig.3.The variations of sensitivity response with wavelength changing for the proposed design in both (a) X-Polarization (b) Y-Polarization

For tuberculosis cell refractive index from 1.345 to 1.349 , sensitivity graph is plotted from wavelength 1.2 to $2.5 \mu \mathrm{m}$. It can be examined that increasing wavelength up to $2.1 \mu \mathrm{m}$ sensitivity increases and then starts to decrease gradually. The reason behind this the fraction of core power reaches its peak value at $2.1 \mu \mathrm{m}$ wavelength due to more light power interaction. While the value of $n_{\text {eff }}$ increases in a continuous way that reduces the relative sensitivity. Hence for both polarizations, 2.1 is chosen operating wavelength. From Fig. 3(a) and 3(b), it can be shown that sensitivity is higher for refractive index 1.349 than other tuberculosis refractive index at optimum wavelength 2.1 for $\mathrm{X}$ polarization. The outcomes are $99.369 \%, 99.31 \%, 99.399 \%, 99.341 \%, 99.356 \%$, respectively, for RI of $1.345,1.346,1.347,1.348$ and 1.349. However, for Y polarization relative sensitivity for 1.349, the refractive index is higher than others due to more interaction of light with the analytes. At optimum wavelength $2.1 \mu \mathrm{m}$, the relative sensitivity is $99.296 \%, 99.31 \%, 99.326 \%, 99.341 \%$, and $99.355 \%$, respectively for investigated RI ranges. However, the variations are minor and for all refractive index value of sensitivity is more than $99 \%$. The highest performance of the relative sensitivity indicates the more effectiveness of the sensor. From Fig, 3 it is noted that the sensitivity response is increasing for the analyte RI change. For the analyte 1.349, 
the maximum relative sensitivity is gained that is indicated with pink color line. These calculated values are showing very high sensitivity more than others prior work.

\subsection{NORMALIZED FREQUENCY}

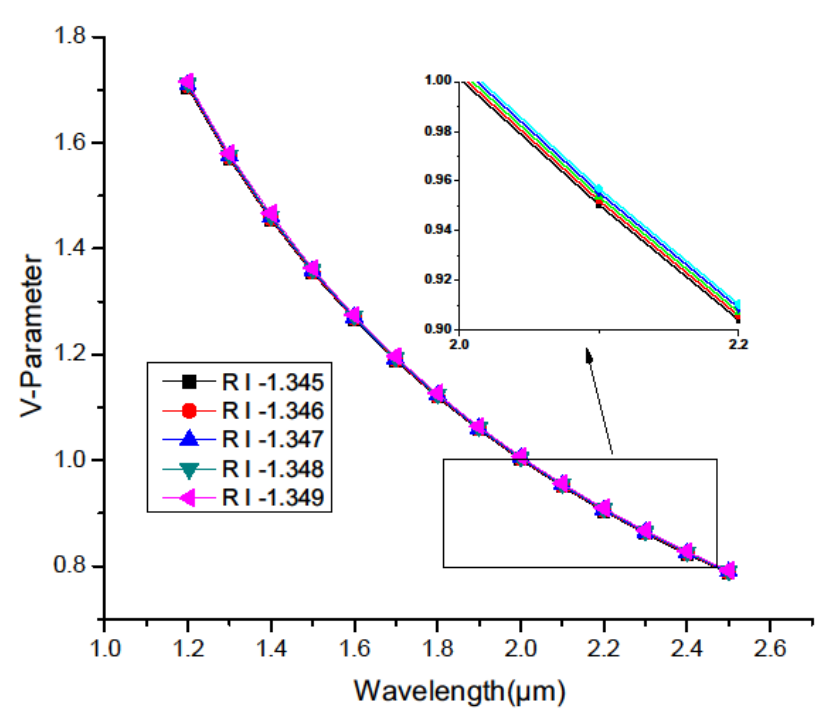

(a)

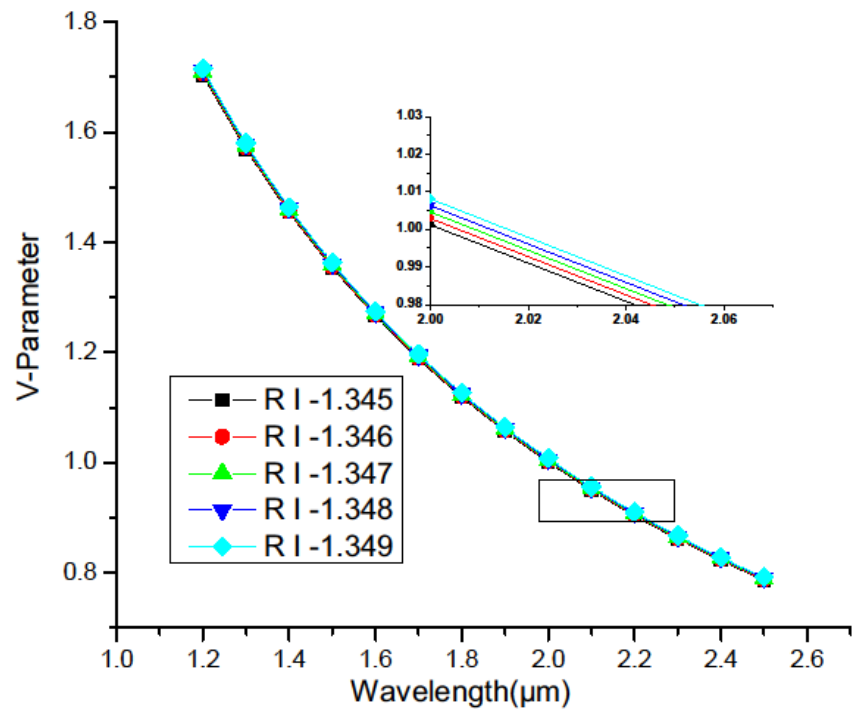

(b)

Figure 4. The variations of V-effective response with wavelength changing for the suggested design in (a) X-Polarization (b) Y-Polarization

The normalized frequency or V-parameter regulates the total modes of optical fiber. The guiding mode is divided into two parts: (1) Single-mode (2) multi-mode. The V-parameter is evaluated by applying the given expression (4). The relation between parameter and wavelength is shown in Fig. 4. It is observed that the presented honeycomb shows the single-mode behaviors through a wavelength region of $1.2 \mu \mathrm{m}$ to $2.5 \mu \mathrm{m}$. From the graph, it is clear that the calculated value is less than 2.405 . Besides, the $\mathrm{V}$ number values are very close to each other. For this reason, the zoom portion is added in the above to understand the differences among them clearly. Hence it exhibits a single modality. Therefore the suggested honeycomb PCF is applicable for long-distance sensing which a good sign of PCF-based sensors. It is clear from the graph value of the V-parameter that it decreases with the increment of wavelength. The maximum value is obtained at $1.2 \mu \mathrm{m}$ for all types of refractive index tuberculosis cells in both(X and $\mathrm{Y})$ polarizations [27]. 


$$
V=\frac{2 \pi \mathrm{R} \pm \sqrt{n_{c o}^{2}-n_{c l}^{2}}}{\lambda}
$$

Here, $\mathrm{n}_{\mathrm{co}}=$ refractive- index of core area whereas $\mathrm{n}_{\mathrm{cl}}=$ refractive-index of the cladding region. Additionally, $\mathrm{R}$ refers to the radius of the proposed sensor structure.

\subsection{CONFINEMENT LOSS}

Confinement loss (CL) is one of the effective parameters in the sensing area. It arises due to the modes leaky nature. Power spread from core to cladding is the main cause of losses known as confinement loss. Its imaginary section of effective refractive- index is considered for the calculation of CL. The expression (5) is used to calculate the loss mechanism [28].

$$
\mathrm{L}_{\mathrm{C}}\left(\frac{\mathrm{dB}}{\mathrm{m}}\right)=\frac{40 \pi \mathrm{I}_{\mathrm{m}}\left(\mathrm{n}_{\mathrm{eff}}\right) 10^{6}}{\lambda \ln (10)}
$$

Here, $L_{c}$ states the CL and $\operatorname{Im}\left(\mathrm{n}_{\text {eff }}\right)$ signifies the imaginary section of the effective refractive- index.
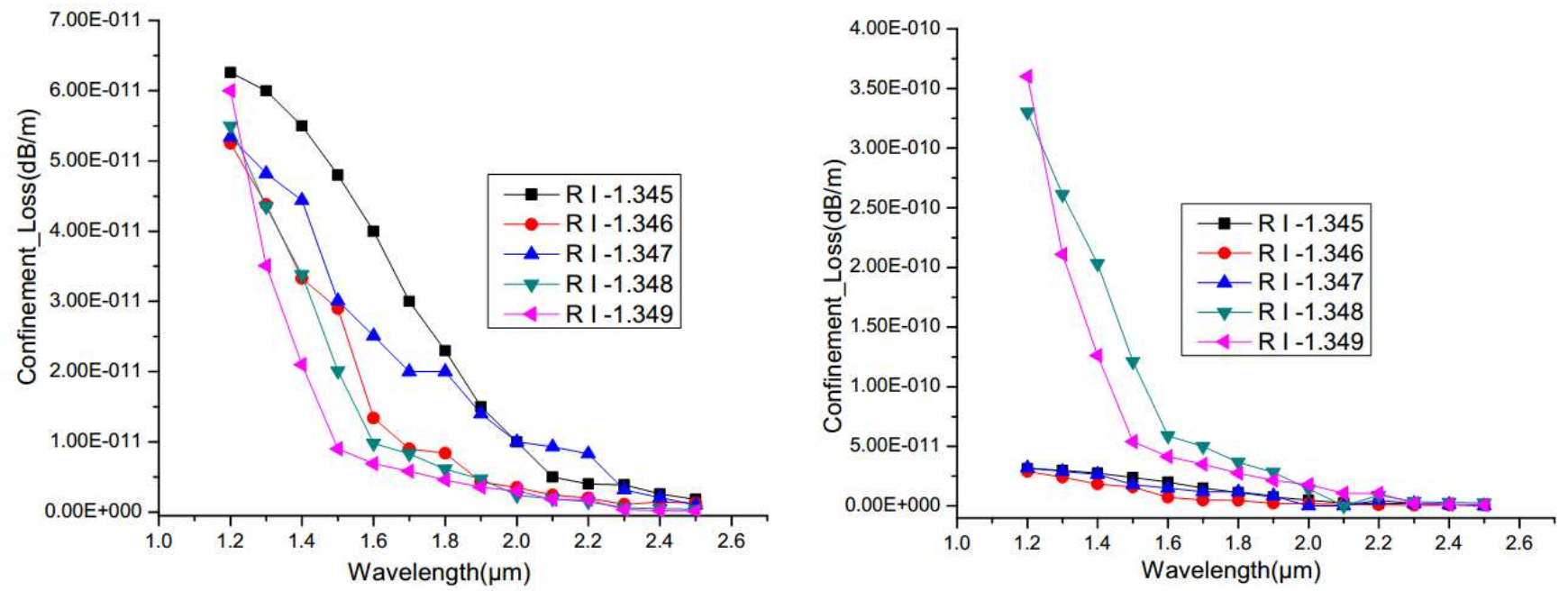

(a)

(b)

Fig.5. The variations of confinement loss response with wavelength changing for the proposed design in both (a) X-Polarization (b) Y-Polarization 
In Fig.5, as shown in the diagram very low confinement loss of order $10^{-12} \mathrm{~dB} / \mathrm{m}$ is occurring due to the tightly bound hexagonal structure in the cladding area. For X polarization at $1.4 \mu \mathrm{m}$ for refractive index 1.345 tuberculosis cell the confinement loss is $3.45 \times 10^{-12} \mathrm{~dB} / \mathrm{m}$. The peak value for the sensor is achieved at wavelength $1.4 \mu \mathrm{m}$ that is the maximum loss for the suggested sensor.

After $1.4 \mu \mathrm{m}$, the value is started to decrease of order $10^{-12} \mathrm{~dB} / \mathrm{m}$. The lowest value of confinement loss of $4.44 \times 10^{-13} \mathrm{~dB} / \mathrm{m}$ is obtained for refractive index value of 1.347 of tuberculosis cell. For Y polarization tuberculosis cell of refractive index 1.345 at $1.4 \mu \mathrm{m}$ is observing confinement loss of $3.45 \times 10^{-12}$. Tuberculosis cell of refractive index 1.346 is observing confinement loss of $8.08425 \times 10^{-12} \mathrm{~dB} / \mathrm{m}$ is attained. At operating wavelength $2.1 \mu \mathrm{m}$ for $\mathrm{X}$ polarization the confinement losses are $1 \times 10^{-12} \mathrm{~dB} / \mathrm{m}, 2.43 \times 10^{-13} \mathrm{~dB} / \mathrm{m}, 3.1 \times 10^{-12} \mathrm{~dB} / \mathrm{m}, 6.9 \times 10^{-13} \mathrm{~dB} / \mathrm{m}$, $4.8 \times 10^{-13} \mathrm{~dB} / \mathrm{m}$ for $1.345,1.346,1.347,1.348$, and 1.349 respectively. For Y-polarization its values are $6 \times 10^{-13} \mathrm{~dB} / \mathrm{m}, 3.3 \times 10^{-13} \mathrm{~dB} / \mathrm{m}, 2.5 \times 10^{-13} \mathrm{~dB} / \mathrm{m}, 2.4 \times 10^{-13} \mathrm{~dB} / \mathrm{m}, 8 \times 10^{-13}$ $\mathrm{dB} / \mathrm{m}, 3.96546 \times 10^{-13} \mathrm{~dB} / \mathrm{m}$ for tuberculosis cell refractive index $1.345,1.346,1.347,1.348$, and 1.349 respectively.

\subsection{SPOT-SIZE PROFILE}

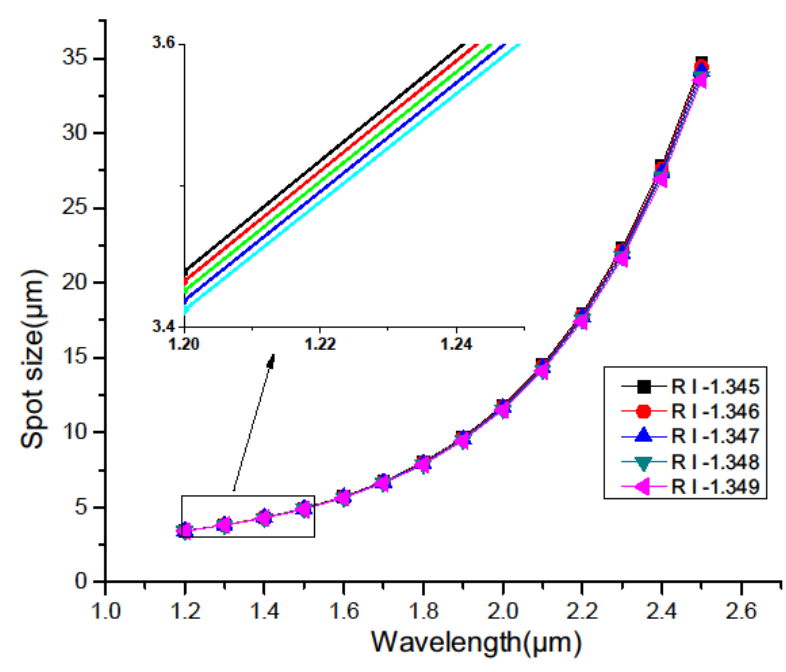

(a)

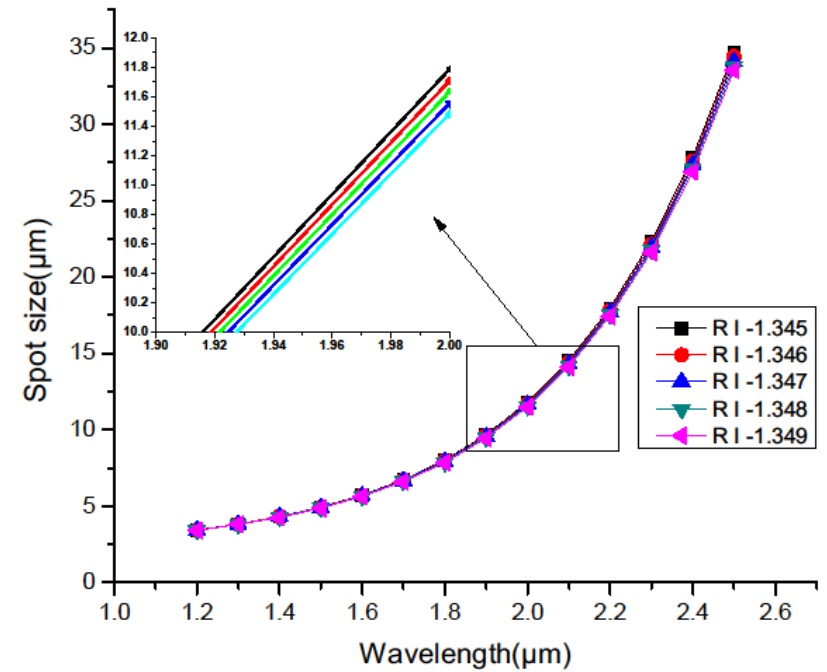

(b) 
Fig.6.The variations of spot size response with wavelength changing for the suggested design in both (a) X-Polarization (b) Y-Polarization[29]

$$
W_{\text {eff }}=R\left(0.65+\frac{1.619}{V^{3 / 2}}+\frac{2.879}{V^{6}}\right)
$$

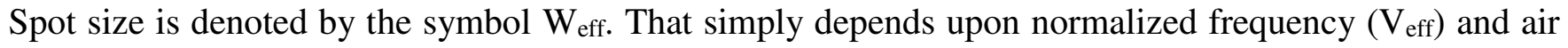
holes radius $(\mathrm{R})$. Spot size is a necessary parameter to calculate beam divergence. Fig. 6 represents the spot size response of the proposed sensor. It is also a significant parameter for calculating various types of losses like scattering loss bending loss and splice loss. Since confinement loss is very low due to tight unique honeycomb structure. Hence, scattering loss is neglected; also bending loss and spice loss is negligible for the considered sensor length.

\subsection{Beam Divergence}

Beam divergence measures the rate by which the beam outspread from the beam diaphragm. Characterization of beam quality is done by measuring divergence. A small value of beam divergence leads to improve beam quality or beam focusing. The decrement of beam divergence increases the beam intensity [30].

$$
A=\tan ^{-1}\left(\frac{\lambda}{\pi W_{e f f}}\right)
$$




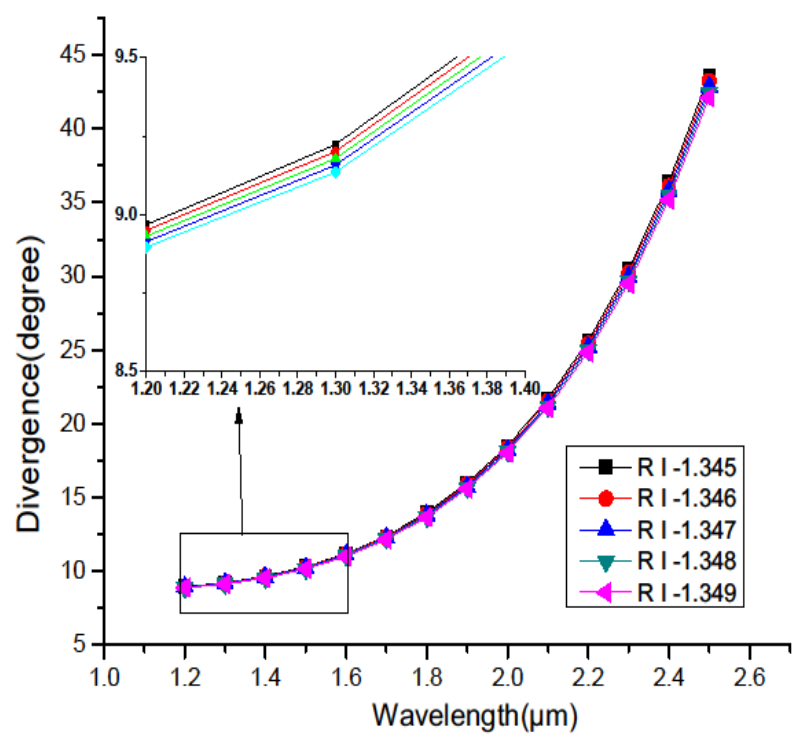

(a)

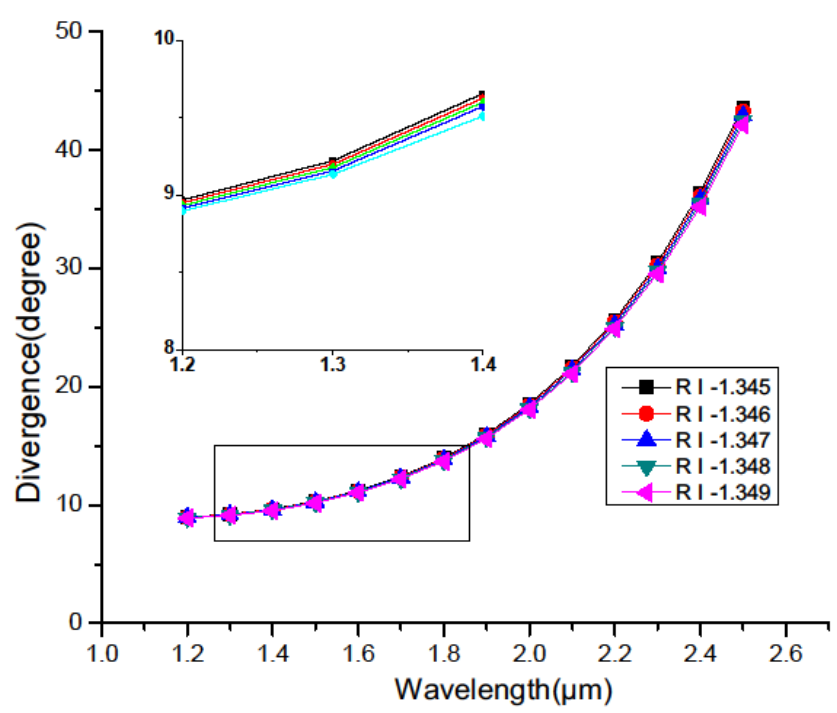

(b)

Fig. 7. The variations of divergence response with wavelength changing for the suggested design in both (a) X-Polarization and (b) Y-Polarization.

From Fig. 7, it can be examined that the beam divergence is 22.5 degrees at $2.1 \mu \mathrm{m}$ wavelength for both polarizations. At $2.1 \mu \mathrm{m}$ wavelength, more light-matter interaction with high quality of the beam and low leakage of power is obtained. That proves that the proposed structure has better optical parameters than other proposed sensors.

\subsection{EFFECTIVE-AREA}

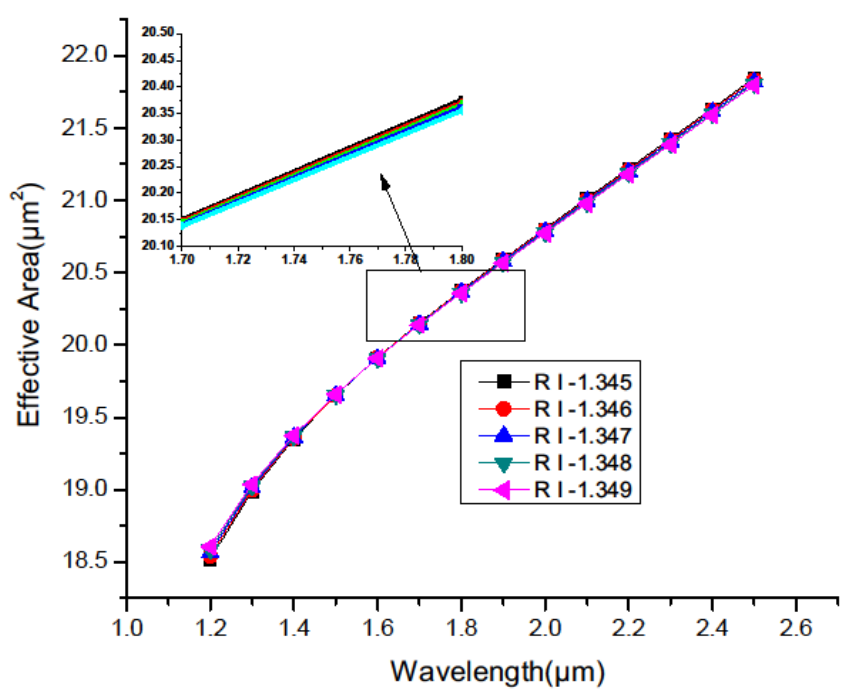

(a)

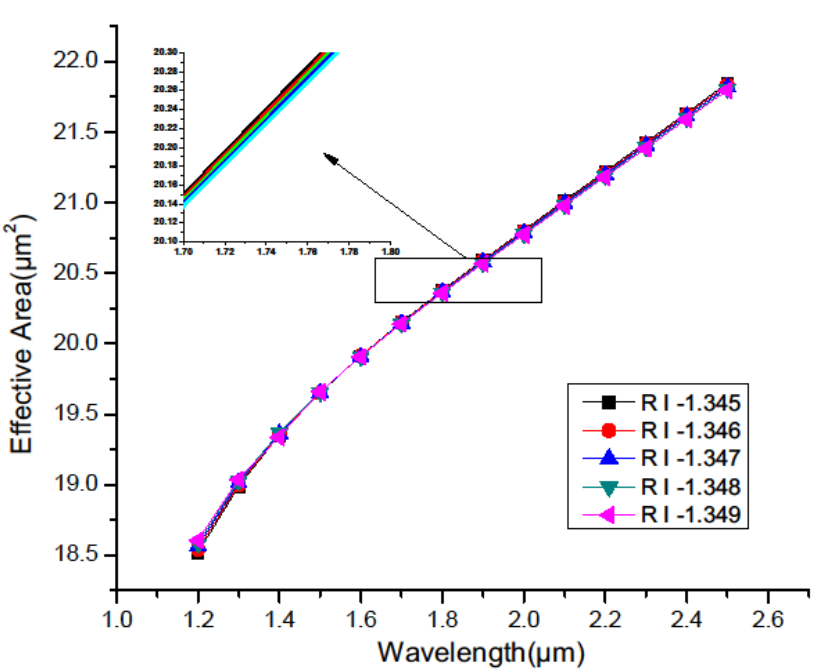

(b) 
Figure 8.The variations of Effective area response with wavelength changing for the presented structure in both (a) X-Polarization (b) Y-Polarization

The symbolic notation of effective mode area is $A_{\text {eff. }}$. For the nonlinearity effect effective area of lower value is more suitable whereas its higher value has application in communication devices. The empirical formula of the effective area is given in equation (8) [31].

$$
A_{\text {eff }}\left(\mu m^{2}\right)=\frac{\left[\int I(r) r d r\right]^{2}}{\left[\int I^{2}(r) r d r\right]^{2}}
$$

Effective mode area is investigated for introduced tuberculosis sensor. Moreover for the proficient transmission of the optical signal, $A_{\text {eff }}$ is a very important parameter. This parameter is obtained from the integration formula. The absolute-Area through which the electromagnetic signal propagates is measured by its given in Eq. (8). From operating wavelength $1.2 \mu \mathrm{m}$ to $2.5 \mu \mathrm{m}$, the effective area of the presented sensor is investigated. An increment in the effective area with a change in wavelength is shown in Fig. 8. A lower value at the lowest wavelength, while its peak value at $2.4 \mu \mathrm{m}$ is obtained. Effective mode area versus wavelength is depicted in the given figure. From the same figure, for the lower range of wavelength transmitted optical wave light confinement into the innermost part of photonic crystal fiber is more tightly. The tight confinement of the transmitted wave into the PCF core region reduces the effective mode area. For the higher range of wavelength light is spread in the outer core region which increases the effective area. A large amount of light accepted by PCF provides better sensing quality since more amount of information is taken by analytes.

\subsection{NUMERICAL APERTURE}

For large sensing applications; the numerical aperture should be higher. The NA of the presented tuberculosis sensor is studied. Formula to calculate numerical aperture is given in the following equation [32].

$$
\mathrm{NA} \approx\left(1+\frac{\pi \mathrm{A}_{\mathrm{eff}}}{\lambda^{2}}\right)^{-\frac{1}{2}}
$$


Here, NA represents the Numerical Aperture of the offered sensor, $A_{\text {eff }}$ indicates the effective area and $\lambda$ specifies the operating wavelength.

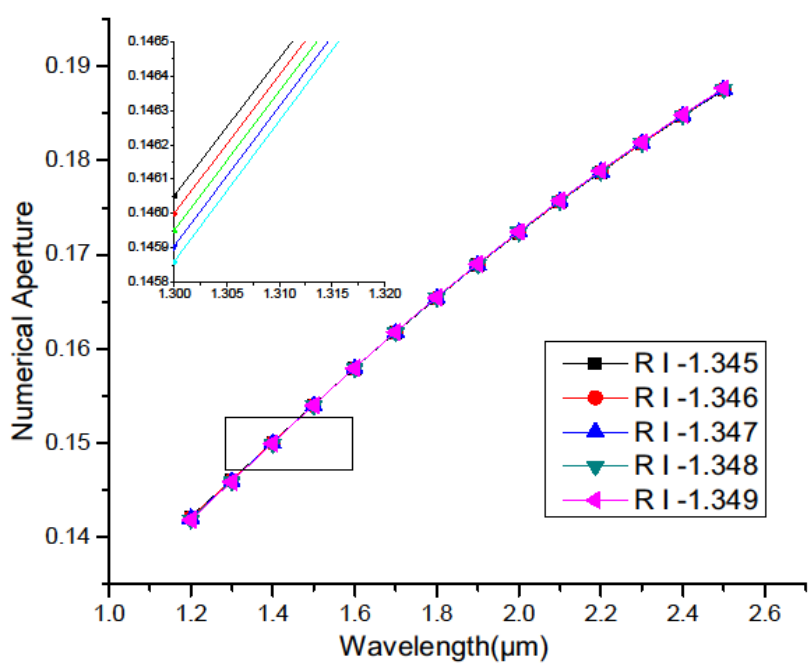

(a)

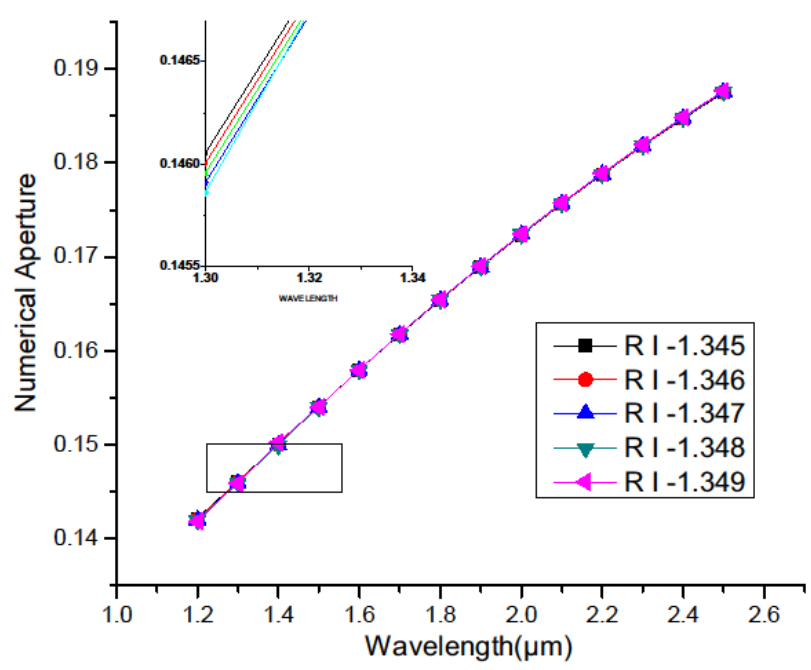

(b)

Fig. 9. The variations of NA response with wavelength changing for the presented structure in both (a) X-Polarization and (b)Y-Polarization

A photonic crystal fiber with a large NA is highly applicable for medical imaging purposes. Numerical Aperture (NA) for the investigated sensor is highlighted in Fig. 9. Additionally, a portion is zoomed and placed above the figure to clearly visualize the variation. At last, the proposed sensor for tuberculosis cell detection demonstrates upgraded relative sensitivity and very low confinement loss with concern to superior beam quality. Also, the mono-mode behavior specifies the analyzed sensor is an auspicious candidate for tuberculosis-sensing applications. Besides, the superior response of spot size, Numerical aperture, effective area supports to prepare the better candidate in the spectroscopy-based sensor. As per my observation, the first time the spectroscopy-based tuberculosis sensor is introduced with high sensitivity (up to 99\%) and very low loss. Thus, it looks like that this suggested sensor has the potential to open a new space in the area of detecting and diagnosing various tuberculosis cells.

\section{Conclusion and Discussion:}

In photonic crystal fiber air holes of various shapes and sizes are present. Several techniques are used to fabricate photonic crystal fiber. Stack and draw method [43] and sol-gel technique [41,42] are some of the important and widely used techniques, however, sol gel technique is mainly applied for manufactur- 
ing silica plates. Its various steps of fabrications are followed by (a) hydrolysis and polycondensation, (b) aging (c) drying (d) densification, and crystallization. Since the cladding area is consisting only hexagonal shape air holes, hence its fabrication is quite simpler and a hollow-core honeycomb structure with silica as background material can be fabricated by the combined effort of the well-known sol-gel method with stack and draw method. However, the main resulting outcomes (from the numerical analysis) of this study are summarized here:

- The relative sensitivity response of the proposed sensor determines the efficiency of the sensor. Application of relative sensitivity functions in parametric optimization of the sensor effectiveness. Based on the highest sensitivity response the sensor efficiency can be determined.

- The step index optical fibers can be differentiated through the V parameter of normalized frequency. There is a cut off value of $\mathrm{V}$ parameter based on this value the kinds of modes are analyzed. As the $\mathrm{V}$ parameter of the proposed sensor indicate that the sensor is a single mode fiber.

- The confinement losses are the losses arises from the light confinement through the core mode. These losses can be increased for various reasons such as structural imperfection, and intrinsic material absorption. Low loss value is necessary to increase the sensing performance.

- Beam divergence is frequently used to describe electromagnetic beams in the optical regime, arises beam is larger with respect to the wavelength. Mainly, its application area is on free-space optical communications. In addition, spot size is another important parameter to calculate the value of beam divergence.

- Effective mode area has a great influence on the measurement of the performance of the proposed fiber sensor. This effective mode area has a wide range of transmission applications.

- Large NA based fibers can be more easily coupled than the small NA fiber. Large NA fibers have various applications on medical imaging purposes, Microscope Objective, and Fiber Optics.

First-time honeycomb-based tuberculosis sensor is investigated for identifying tuberculosis cell with all essential parameters such as sensitivity, confinement loss, effective area V-parameter, the numerical aperture of silica-based PCF at the operating wavelength of $1.2 \mu \mathrm{m}$ to $2.4 \mu \mathrm{m}$ for both $\mathrm{X}$ and Y polarizations. Maximum sensitivity response is gained up to $99 \%$ and very low confinement loss of order $10^{-11}$. Besides, the mono-mode character of the suggested honeycomb PCF over the whole range of operating wavelength is a very good sign of being a good sensor. The proposed sensor shows better outcomes than the previous works. This sensor is also applicable for practical purposes. The tuberculosis sensor with excellent optical properties makes it a prominent candidate in sensing applications. As a result, the mod- 
ified simulated structure can be also helpful for further biotechnology as well as medical technology. In addition, the connection between the circadian rhythm (phase shifting [33]) and bacterial resistance is still unknown to the researchers but few pieces of evidence [34, 35] and the relation with evoked response potentials $[36,37]$ is in progress $[38,39,40]$. However, this study does not count circadian rhythm or evoked potentials but could be helpful for such studies. Note here that there are a large number of parameters are analyzed to design a sensor that is capable of diagnosing various tuberculosis cells. Additionally, the sensor has a great impact on the field of medical technology. In the future, based on this type of structure new type of sensors can be also designed.

\section{Acknowledgement}

This work was supported in part by funding from the Natural Sciences and Engineering Research Council of Canada (NSERC).

\section{REFERENCES}

[1] Bradley, T.D., Wang, Y., Alharbi, M., Debord, B., Fourcade-Dutin, C., Beaudou, B., Gerome, F. and Benabid, F., 2013. Optical properties of low loss (70dB/km) hypocycloid-core Kagome hollow core photonic crystal fiber for $\mathrm{Rb}$ and $\mathrm{Cs}$ based optical applications. Journal of Lightwave Technology, 31(16), pp.2752-2755.

[2] Sharma, M., Borogohain, N. and Konar, S., 2013. Index guiding photonic crystal fibers with large birefringence and walk-off. Journal of lightwave technology, 31(21), pp.3339-3344.

[3] Kwon, Y., Park, K., Hong, S. and Jeong, Y., 2017. Numerical study on the supercontinuum generation in an active highly nonlinear photonic crystal fiber with flattened all-normal dispersion. IEEE Journal of Quantum Electronics, 53(5), pp.1-8.

[4] Chen, H., Li, S., Li, J., Han, Y. and Wu, Y., 2014. High sensitivity of temperature sensor based on ultracompact photonics crystal fibers. IEEE Photonics Journal, 6(6), pp.1-6.

[5] Ayyanar, N., Vigneswaran, D., Sharma, M., Sumathi, M., Rajan, M.M. and Konar, S., 2016. Hydrostatic pressure sensor using high birefringence photonic crystal fibers. IEEE Sensors Journal, 17(3), pp.650-656.

[6] Vigneswaran, D., Ayyanar, N., Sharma, M., Sumathi, M., Rajan, M. and Porsezian, K., 2018. Salinity sensor using photonic crystal fiber. Sensors and Actuators A: Physical, 269, pp.22-28. 
[7] Ahmed, K., Ahmed, F., Roy, S., Paul, B.K., Aktar, M.N., Vigneswaran, D. and Islam, M.S., 2019. Refractive index-based blood components sensing in terahertz spectrum. IEEE Sensors Journal, 19(9), pp.3368-3375.

[8] Qin, J., Zhu, B., Du, Y. and Han, Z., 2019. Terahertz detection of toxic gas using a photonic crystal fiber. Optical Fiber Technology, 52, p.101990.

[9] Islam, M.S., Sultana, J., Dinovitser, A., Ahmed, K., Ng, B.W.H. and Abbott, D., 2018. Sensing of toxic chemicals using polarized photonic crystal fiber in the terahertz regime. Optics Communications, 426, pp.341-347.

[10] Atiqullah, S.M., Palit, A., Reja, M.I., Akhtar, J., Fatema, S. and Absar, R., 2019. Detection of harmful food additives using highly sensitive photonic crystal fiber. Sensing and Bio-Sensing Research, 23, p.100275.

[11] Ramanujam, N.R., Patel, S.K., Reddy, N.M., Taya, S.A., Vigneswaran, D. and Rajan, M.M., 2020. One-dimensional ring mirror-defect photonic crystal for detection of mycobacterium tuberculosis bacteria. Optik, 219, p.165097.

[12] World Health Organization, 1999. The world health report: 1999: making a difference. World Health Organization.

[13] Srivastava, S.K., Van Rijn, C.J. and Jongsma, M.A., 2016. Biosensor-based detection of tuberculosis. RSC advances, 6(22), pp.17759-17771.

[14] Trzaskowski, M., Napiórkowska, A., Augustynowicz-Kopeć, E. and Ciach, T., 2018. Detection of tuberculosis in patients with the use of portable SPR device. Sensors and Actuators B: Chemical, 260, pp.786-792.

[15] Noordhoek, G.T., Kolk, A.H., Bjune, G., Catty, D., Dale, J.W., Fine, P.E., Godfrey-Faussett, P., Cho, S.N., Shinnick, T. and Svenson, S.B., 1994. Sensitivity and specificity of PCR for detection of Mycobacterium tuberculosis: a blind comparison study among seven laboratories. Journal of Clinical Microbiology, 32(2), pp.277-284.

[16] Arora, K., Chand, S. and Malhotra, B.D., 2006. Recent developments in bio-molecular electronics techniques for food pathogens. Analytica Chimica Acta, 568(1-2), pp.259-274.

[17] Jabin, M.A., Ahmed, K., Rana, M.J., Paul, B.K., Islam, M., Vigneswaran, D. and Uddin, M.S., 2019. Surface plasmon resonance based titanium coated biosensor for cancer cell detection. IEEE Photonics J, 11(4), pp.1-10.

[18] Islam, M.S., Sultana, J., Ahmed, K., Islam, M.R., Dinovitser, A., Ng, B.W.H. and Abbott, D., 2017. A novel approach for spectroscopic chemical identification using photonic crystal fiber in the terahertz regime. IEEE Sensors Journal, 18(2), pp.575-582. 
[19] Hsu, S.H., Hung, S.C., Chen, Y.K. and Jian, Z.H., 2015. Surface plasmon resonator using high sensitive resonance telecommunication wavelengths for DNA sensors of Mycobacterium tuberculosis with thiol-modified probes. Sensors, 15(1), pp.331-340.

[20] Zhang, Q., Yang, X., Li, P., Huang, G., Feng, S., Shen, C., Han, B., Zhang, X., Jin, F., Xu, F. and $\mathrm{Lu}, \mathrm{T} . J ., 2015$. Bioinspired engineering of honeycomb structure-Using nature to inspire human innovation. Progress in Materials Science, 74, pp.332-400.

[21] Ahmed, K., Islam, M.I., Paul, B.K., Islam, M.S., Sen, S., Chowdhury, S., Uddin, M.S., Asaduzzaman, S. and Bahar, A.N., 2017. Effect of photonic crystal fiber background materials in sensing and communication applications. Materials discovery, 7, pp.8-14.

[22] Mitu, S.A., Dey, D.K., Ahmed, K., Paul, B.K., Luo, Y., Zakaria, R. and Dhasarathan, V., 2020. $\mathrm{Fe} 3 \mathrm{O} 4$ nanofluid injected photonic crystal fiber for magnetic field sensing applications. Journal of Magnetism and Magnetic Materials, 494, p.165831.

[23] Akowuah, E.K., Ademgil, H., Haxha, S. and AbdelMalek, F., 2009. An endlessly single-mode photonic crystal fiber with low chromatic dispersion, and bend and rotational insensitivity. Journal of lightwave technology, 27(17), pp.3940-3947.

[24] De, M. and Singh, V.K., 2019. Multi-purpose photonic crystal fiber having advanced optical properties and long sensing range. Photonics and Nanostructures-Fundamentals and Applications, 36, p.100722.

[25] Islam, M.S., Sultana, J., Ahmed, K., Islam, M.R., Dinovitser, A., Ng, B.W.H. and Abbott, D., 2017. A novel approach for spectroscopic chemical identification using photonic crystal fiber in the terahertz regime. IEEE Sensors Journal, 18(2), pp.575-582.

[26] Asaduzzaman, S., Ahmed, K., Bhuiyan, T. and Farah, T., 2016. Hybrid photonic crystal fiber in chemical sensing. SpringerPlus, 5(1), pp.1-11.

[27] Ahmed, F., Roy, S., Paul, B.K., Ahmed, K. and Bahar, A.N., 2020. Extremely low loss of photonic crystal fiber for terahertz wave propagation in optical communication applications. Journal of Optical Communications, 41(4), pp.393-401.

[28] Leon, M.J.B.M. and Kabir, M.A., 2020. Design of a liquid sensing photonic crystal fiber with high sensitivity, bireferingence \& low confinement loss. Sensing and Bio-Sensing Research, 28, p.100335.

[29] Ahmed, K., Ahmed, F., Roy, S., Paul, B.K., Aktar, M.N., Vigneswaran, D. and Islam, M.S., 2019. Refractive index-based blood components sensing in terahertz spectrum. IEEE Sensors Journal, 19(9), pp.3368-3375. 
[30] Inci, H.D. and Ozsoy, S., 2012. A theoretical study of large solid-core square-lattice silica photonic crystal fibers with square air-holes. Optical Materials, 35(2), pp.205-210.

[31] Islam, R., Habib, M.S., Hasanuzzaman, G.K.M., Rana, S., Sadath, M.A. and Markos, C., 2016. A novel low-loss diamond-core porous fiber for polarization maintaining terahertz transmission. IEEE Photonics Technology Letters, 28(14), pp.1537-1540.

[32] Chowdhury, S., Sen, S., Ahmed, K. and Asaduzzaman, S., 2017. Design of highly sensible porous shaped photonic crystal fiber with strong confinement field for optical sensing. Optik, 142, pp.541-549.

[33] Tahereh Tekieh, Steven W Lockley, Peter A Robinson, Stephen McCloskey, M S Zobaer, Svetlana Postnova, 2000. Modeling melanopsin-mediated effects of light on circadian phase, melatonin suppression, and subjective sleepiness. Journal of Pineal Research 69 (3), e12681

[34] Abnave, P., Mottola, G., Gimenez, G., Boucherit, N., Trouplin, V., Torre, C., Conti F., Ben Amara A., Lepolard, C., Djian, B., Hamaoui, D., Mettouchi, A., Kumar, A., Pagnotta, S., Bonatti, S., Lepidi, H., Salvetti, A., Abi-Rached, L., Lemichez, E., Mege, JL., Ghigo, E., 2014. Screening in planarians identifies MORN2 as a key component in LC3-associated phagocytosis and resistance to bacterial infection. Cell Host Microbe. 16(3):338-50.

[35] Itoh MT, Shinozawa T, and Sumi Y, 1999. Circadian rhythms of melatonin-synthesizing enzyme activities and melatonin levels in planarians. Brain Res. 830(1): pp 165-73.

[36] Zobaer M S, Robinson P A, Kerr C C, 2018. Physiology-based ERPs in normal and abnormal states; Biological Cybernetics; 112 (5), pp 465-482.

[37] Zobaer M S, Anderson R M, Kerr C C, Robinson P A, Wong K K H, D’Rozario A L D, 2017. Kcomplexes, spindles, and ERPs as impulse responses: unification via neural filed theory; Biological Cybernetics, 111 (2), pp 149-164 (2017).

[38] Kalita J, Misra UK. Rapid diagnosis of tuberculosis meningitis by polymerase chain reaction. Neurol India 49(1), pp 51-4.

[39] Mark Banoub, John E. Tetzlaff, Armin Schubert, 2003. Pharmacologic and Physiologic Influences Affecting Sensory Evoked Potentials: Implications for Perioperative Monitoring. Anesthesiology 99, pp 716-737

[40] Creel DJ, 2019. Visually evoked potentials. Handb Clin Neurol. 160, pp 501-522.

[41] Abdel Salam Hamdy Makhlouf, Rocio Rodriguez, 2020. Chapter 15 - Bioinspired smart coatings and engineering materials for industrial and biomedical applications. Editor(s): Abdel Salam Hamdy Makhlouf, Nedal Y. Abu-Thabit. Advances in Smart Coatings and Thin Films for Future Industrial and Biomedical Engineering Applications. Elsevier, pages 407-427 
[42] Brinker CJ, KeeferDale KD, SchaeferDale W, Schaefer W, Ashley CS, 1982. Sol-Gel Transition in Simple Silicates. J. Non-Crystalline Solids, 48, pp 47.

[43] Pysz D, Kujawa I, Stepien R, Klimczak M, Filipkowski A, Franczyk M, Kociszewski L, Buzniak J, Haraśny K, Buczynski R, 2014. Stack and draw fabrication of soft glass microstructured fiber optics. Bulletin of The Polish Academy of Sciences-technical Sciences 62, pp 667-682.

[44] Schmidt-Schultz, TH., Schultz, M., 2015. AG 85, a major secretion protein of Mycobacterium tuberculosis, can be identified in ancient bone. Tuberculosis (Edinb) 95 (1), pp S87-92.

[45] Gorachand, G., 1997. Sellmeier Coefficients and Dispersion of Thermo-Optic coefficients for some optical glasses. Applied Optics 36 (7), pp 1540-6. 
Figures

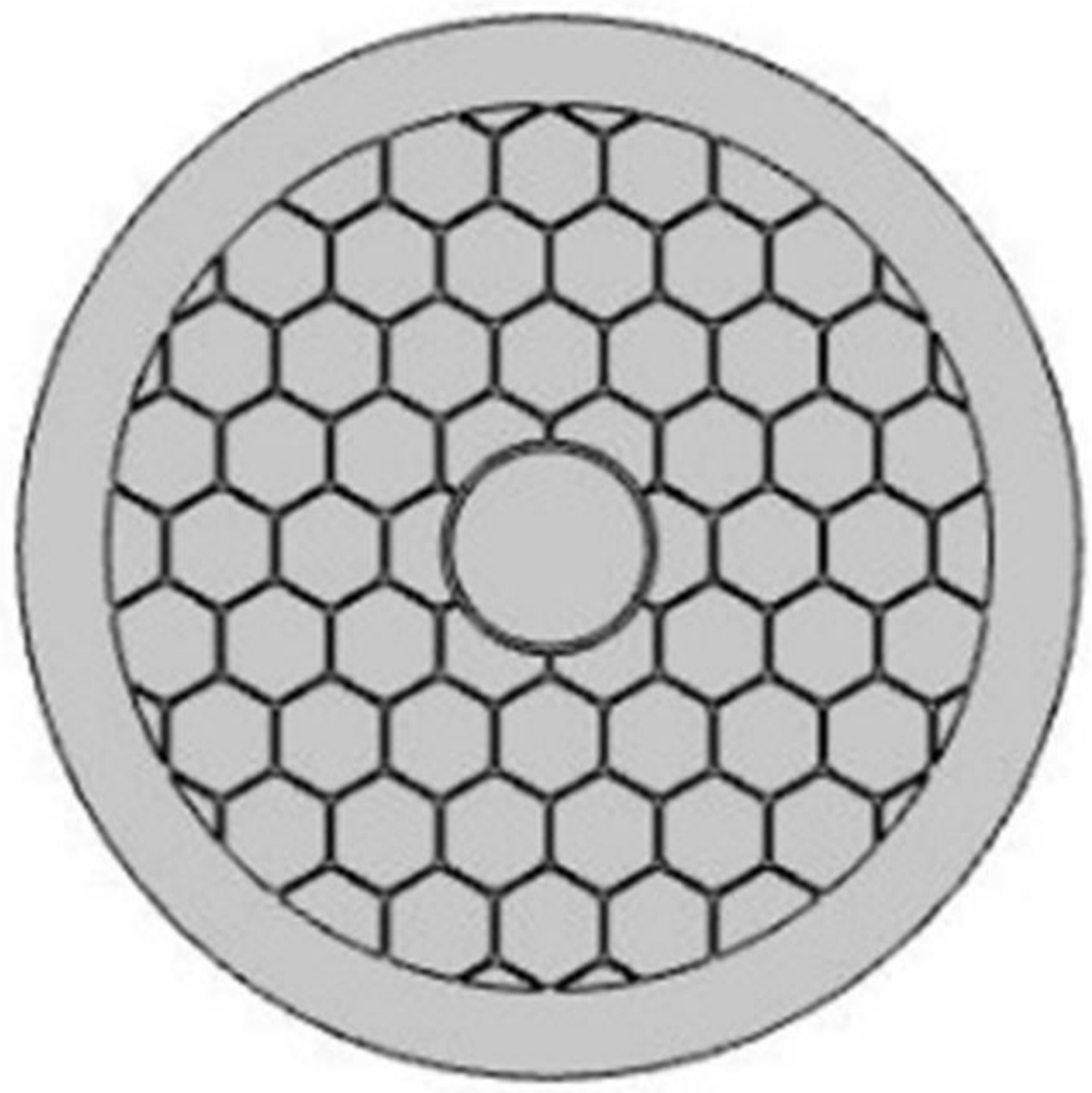

Figure 1

The proposed tuberculosis sensor design by indicating analyte region 


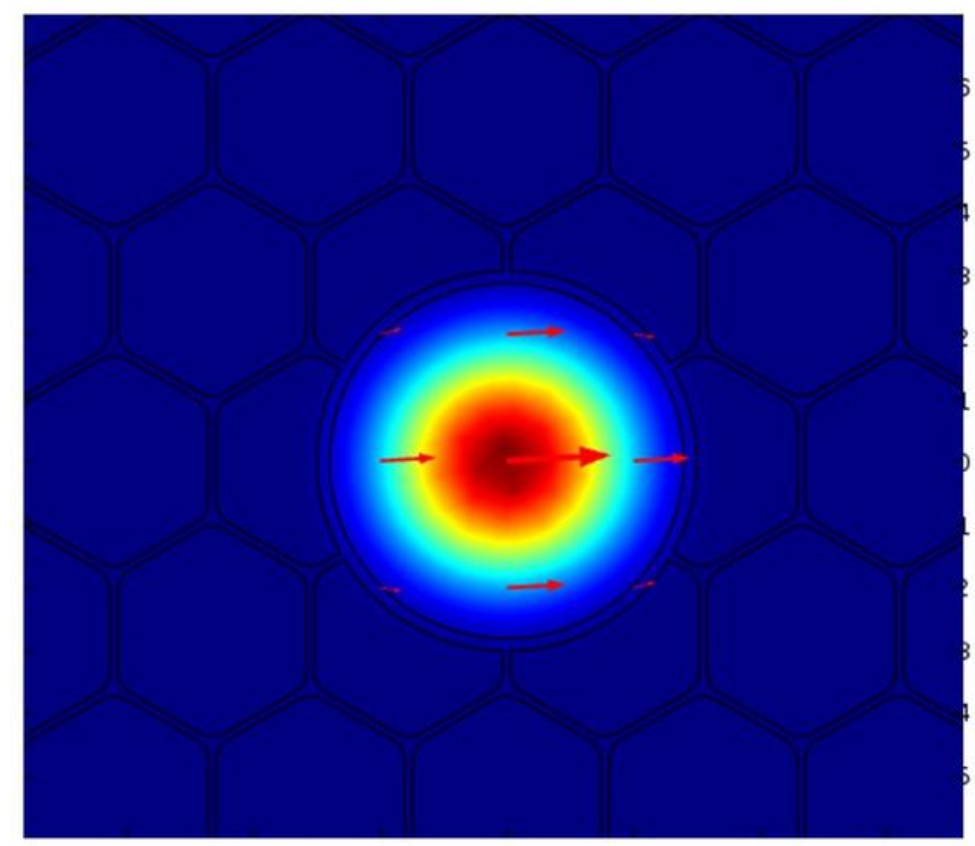

(a)

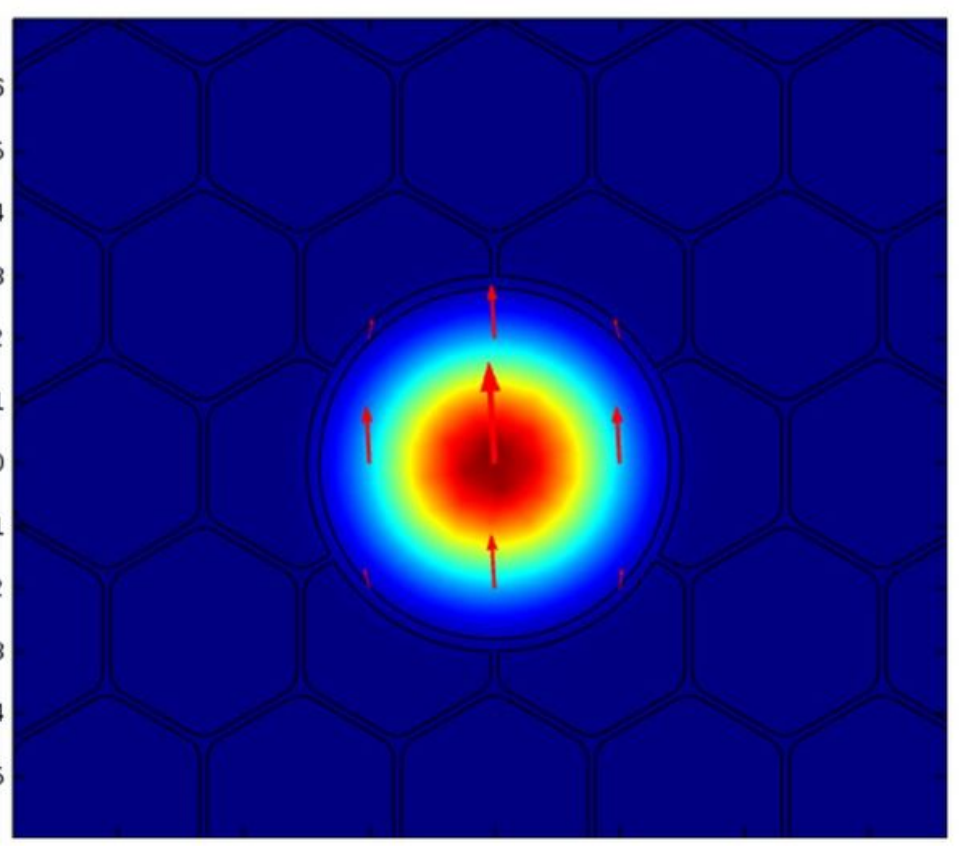

(b)

\section{Figure 2}

Fundamental mode intensity distribution of presented sensor in both (a) X-polarization (b) Y-polarization

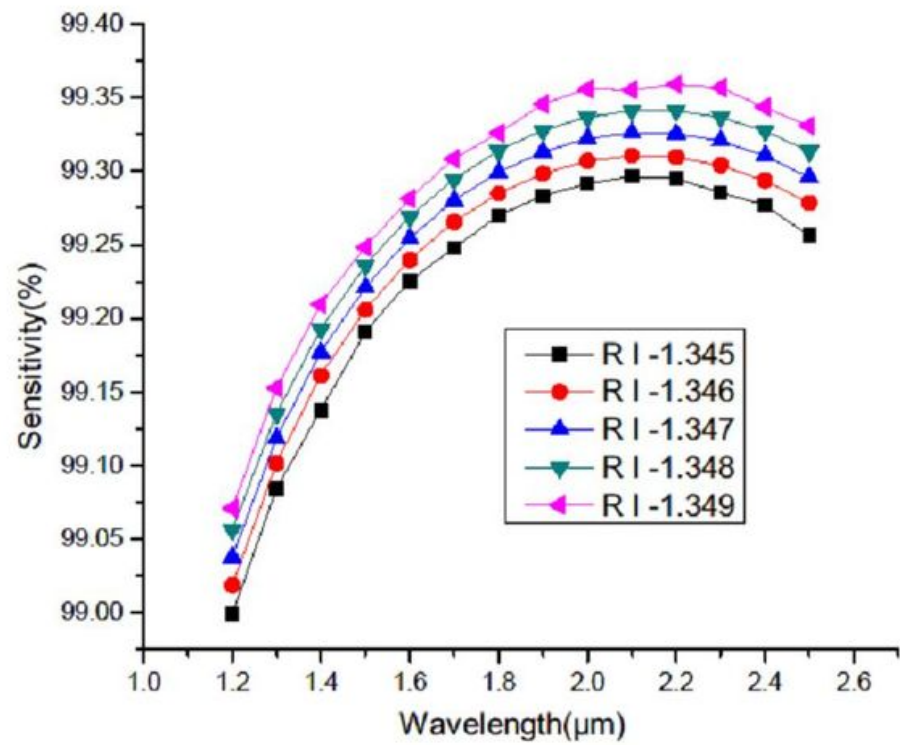

a)

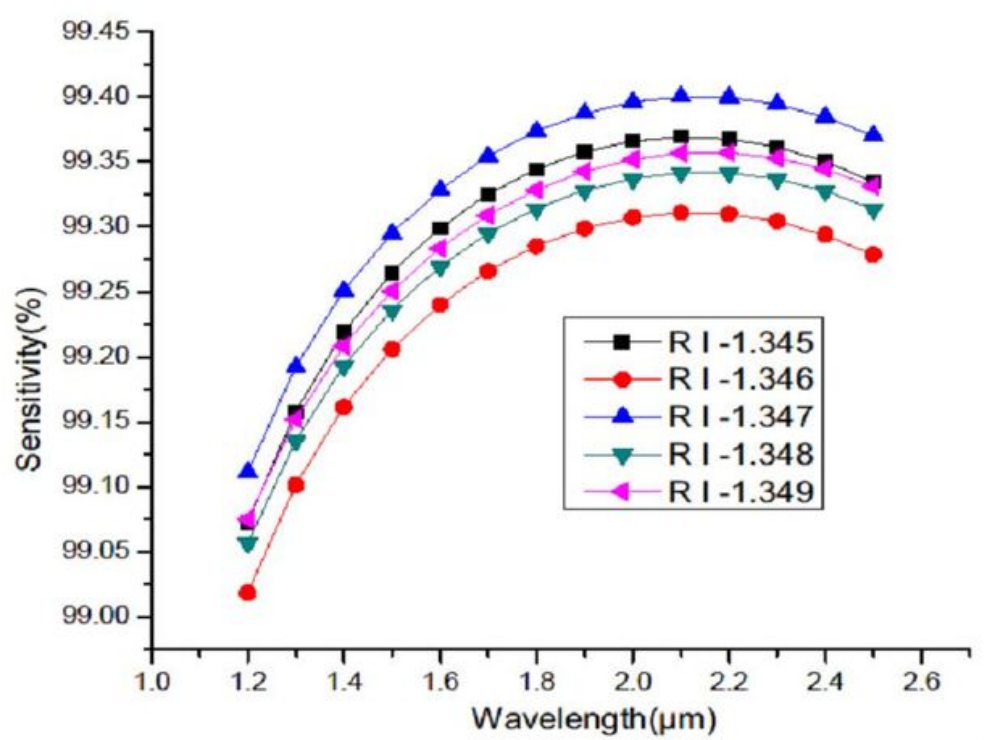

(b)

\section{Figure 3}

The variations of sensitivity response with wavelength changing for the proposed design in both (a) XPolarization (b) Y-Polarization 


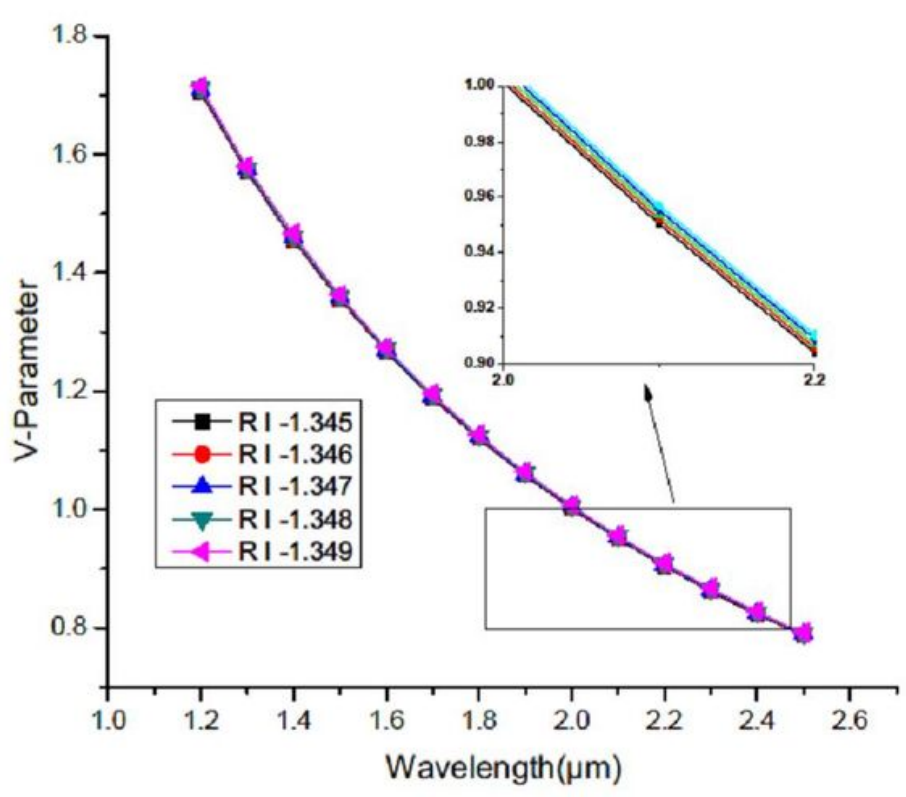

(a)

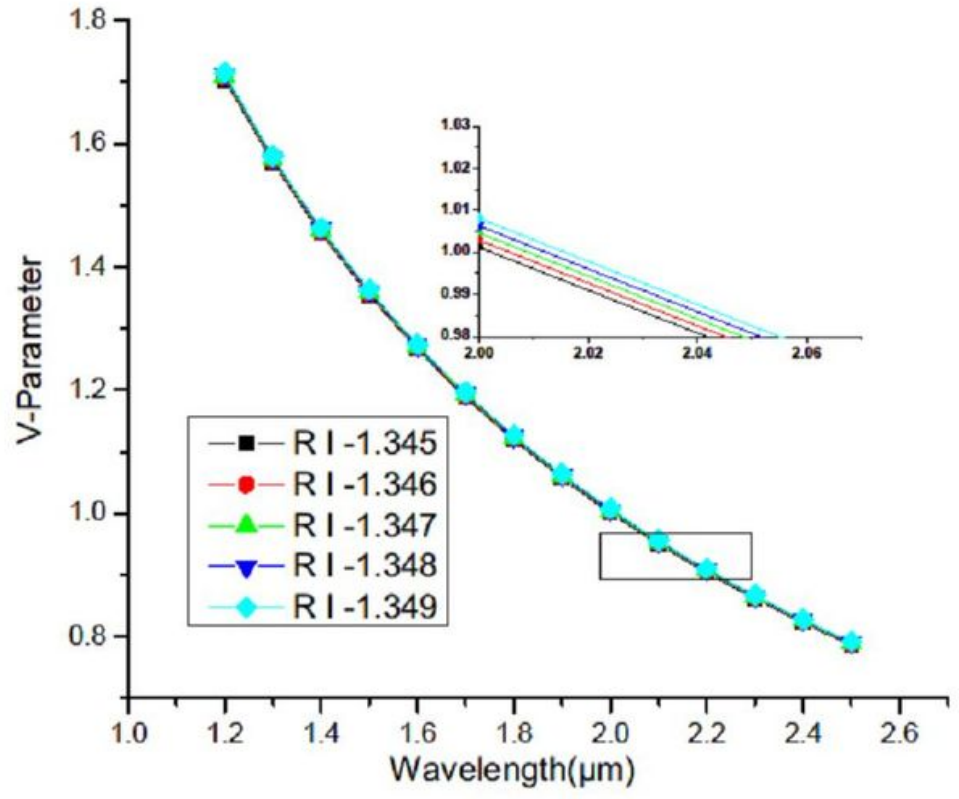

(b)

\section{Figure 4}

The variations of V-effective response with wavelength changing for the suggested design in (a) XPolarization (b) Y-Polarization
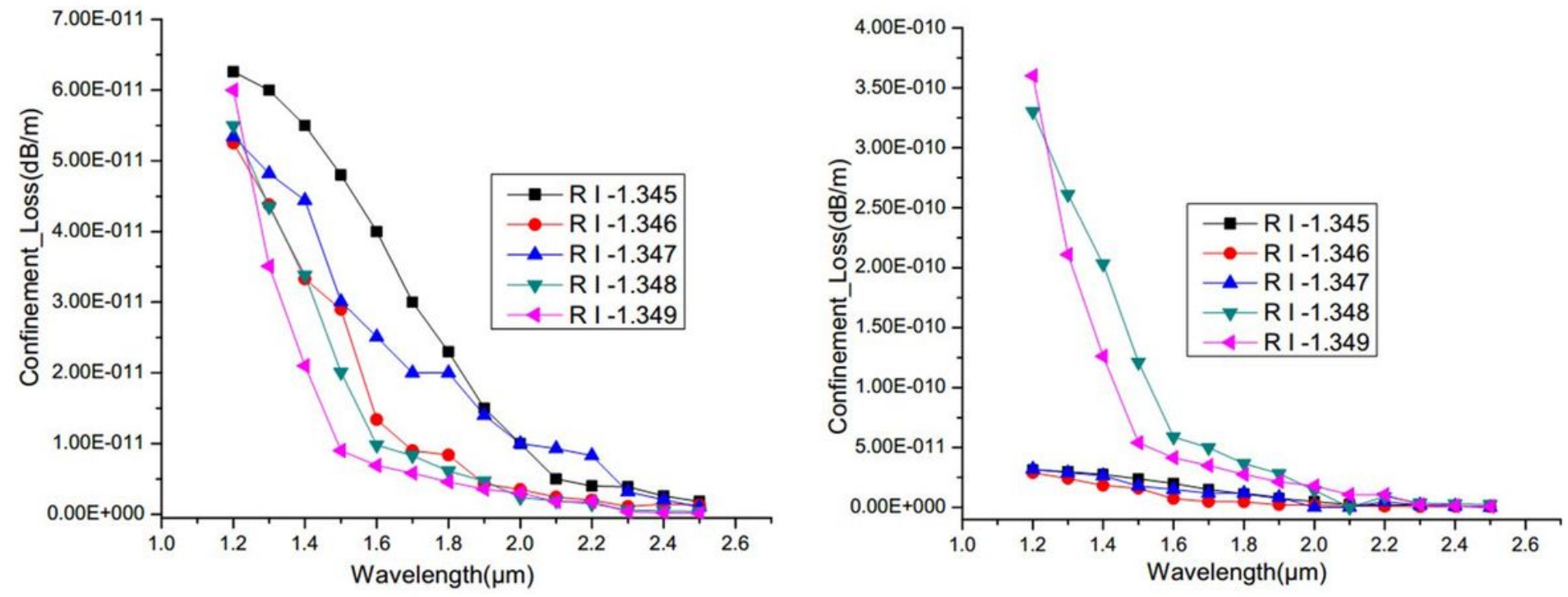

(a)

(b)

\section{Figure 5}

The variations of confinement loss response with wavelength changing for the proposed design in both (a) X-Polarization (b) Y-Polarization 


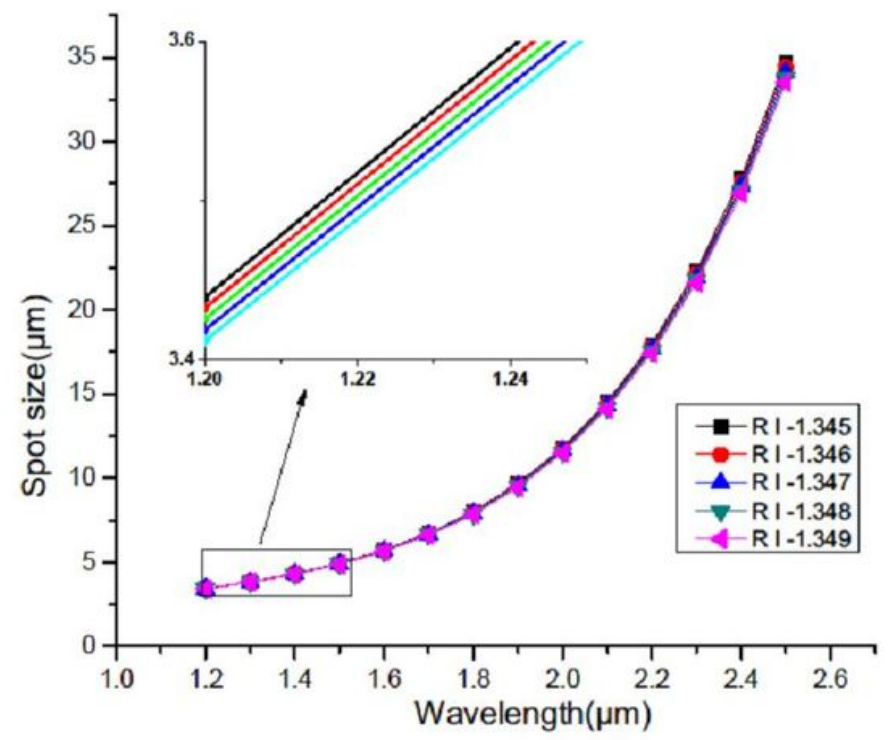

(a)

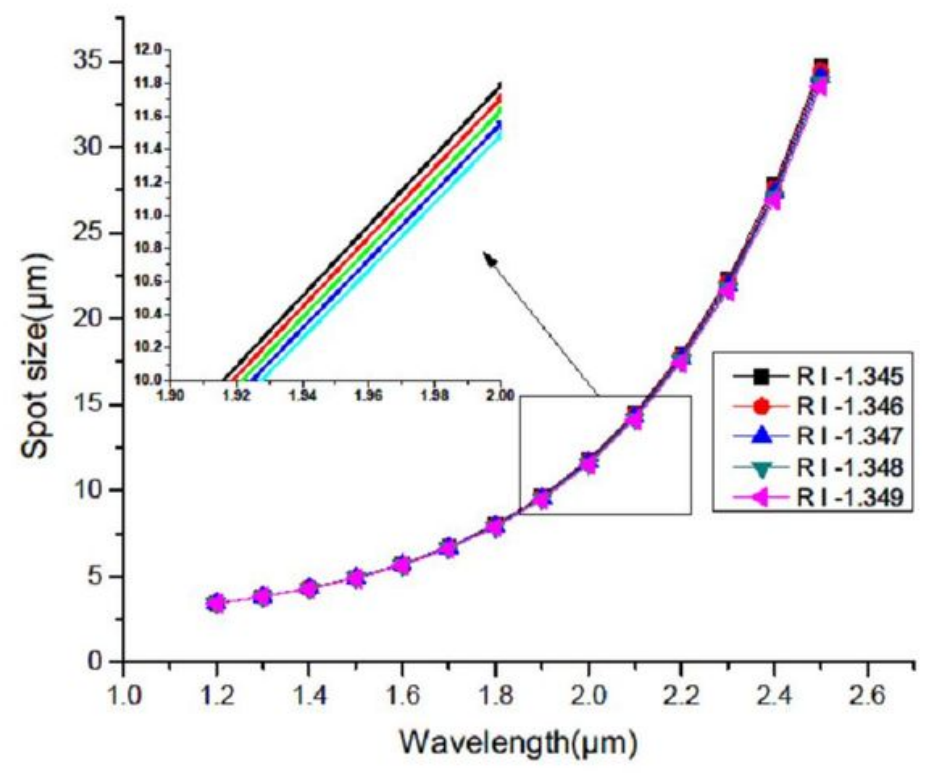

(b)

Figure 6

The variations of spot size response with wavelength changing for the suggested design in both (a) XPolarization (b) Y-Polarization[29]

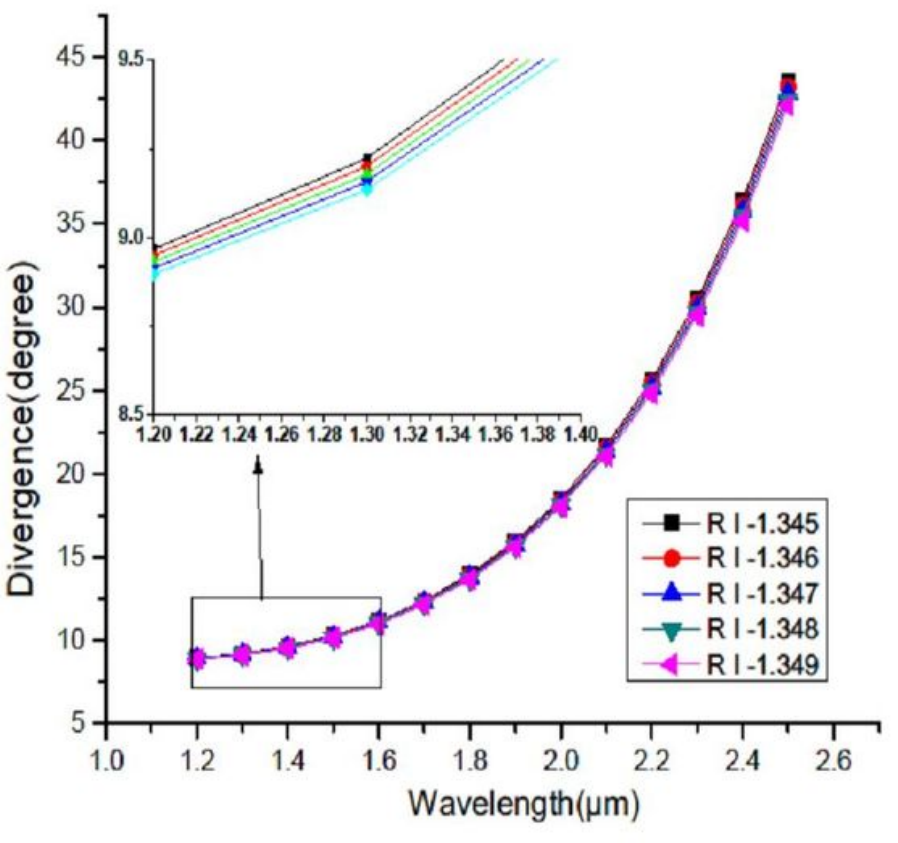

(a)

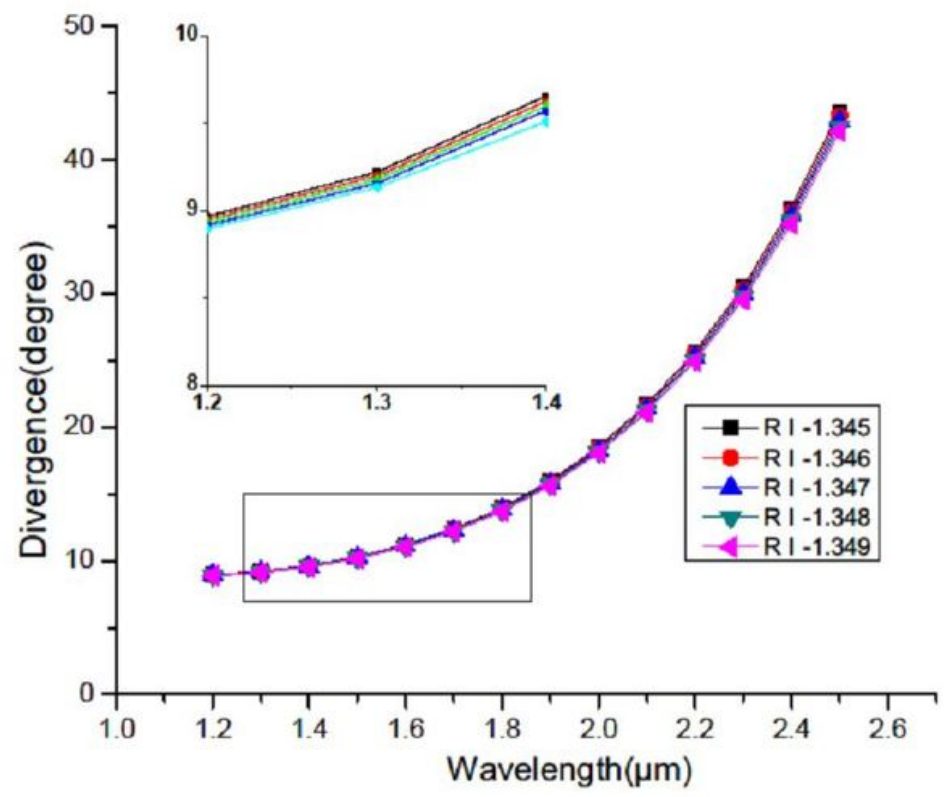

(b)

\section{Figure 7}

The variations of divergence response with wavelength changing for the suggested design in both (a) XPolarization and (b) Y-Polarization. 


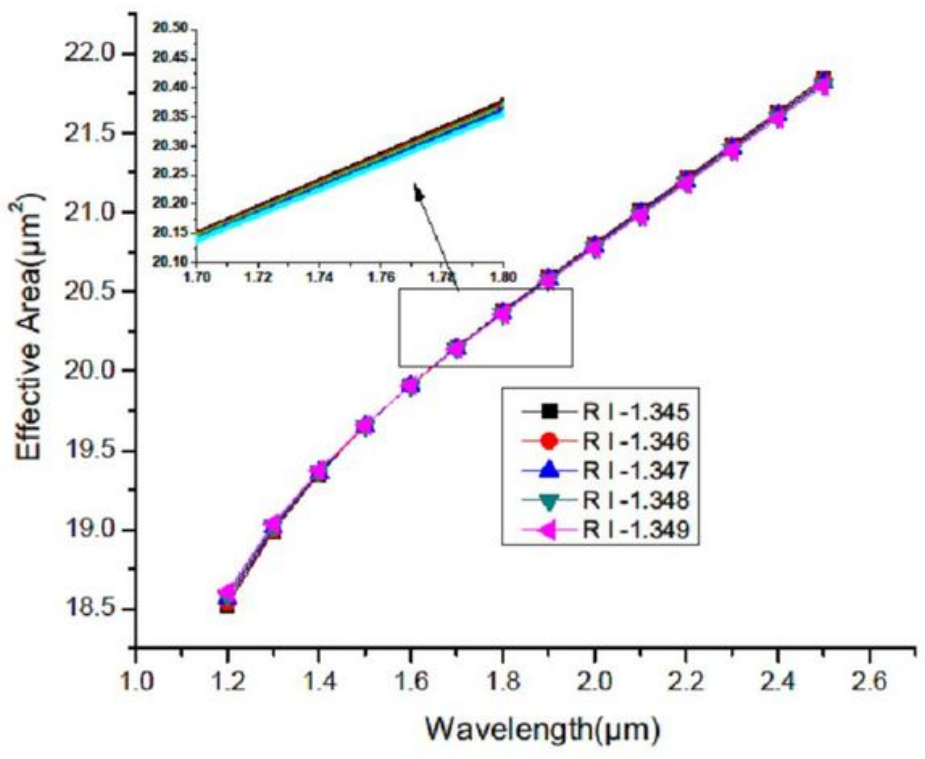

(a)

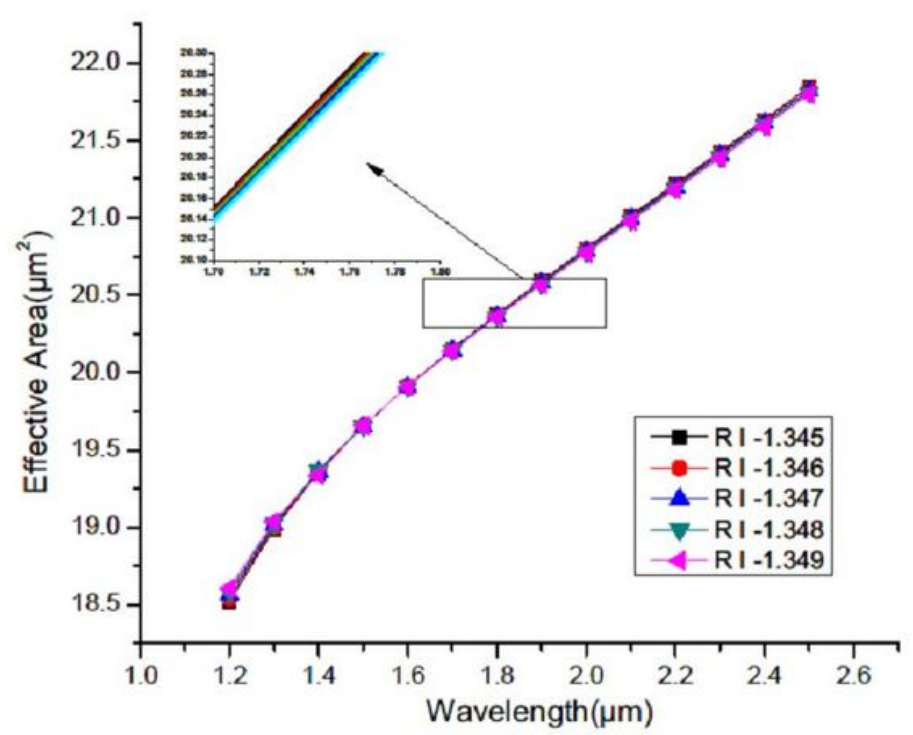

(b)

\section{Figure 8}

The variations of Effective area response with wavelength changing for the presented structure in both (a) X-Polarization (b) Y-Polarization

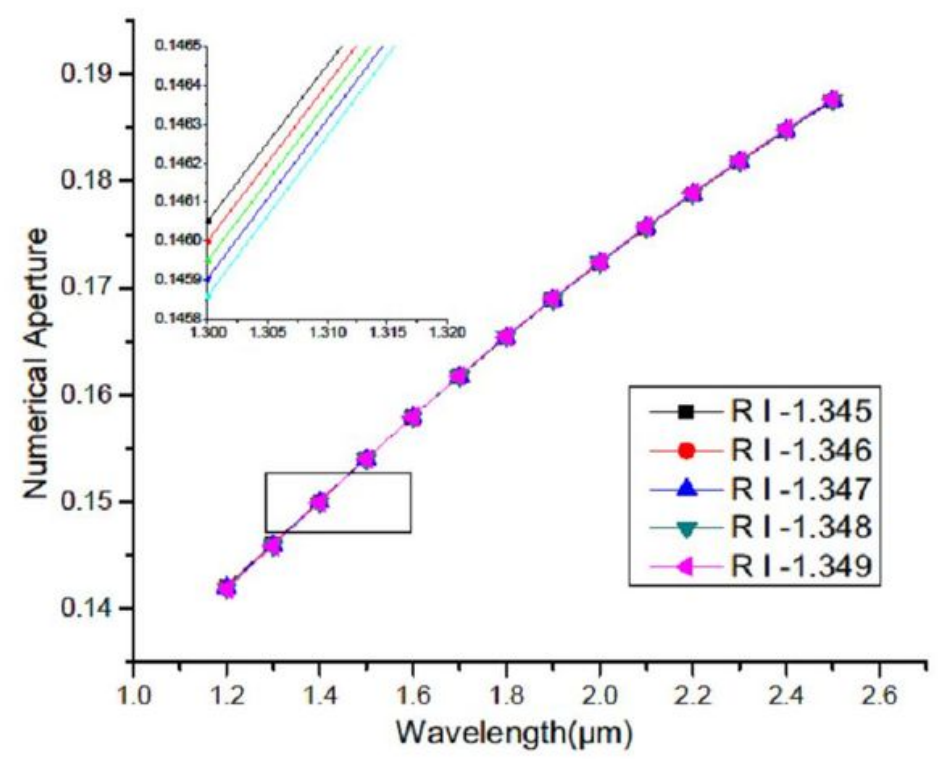

(a)

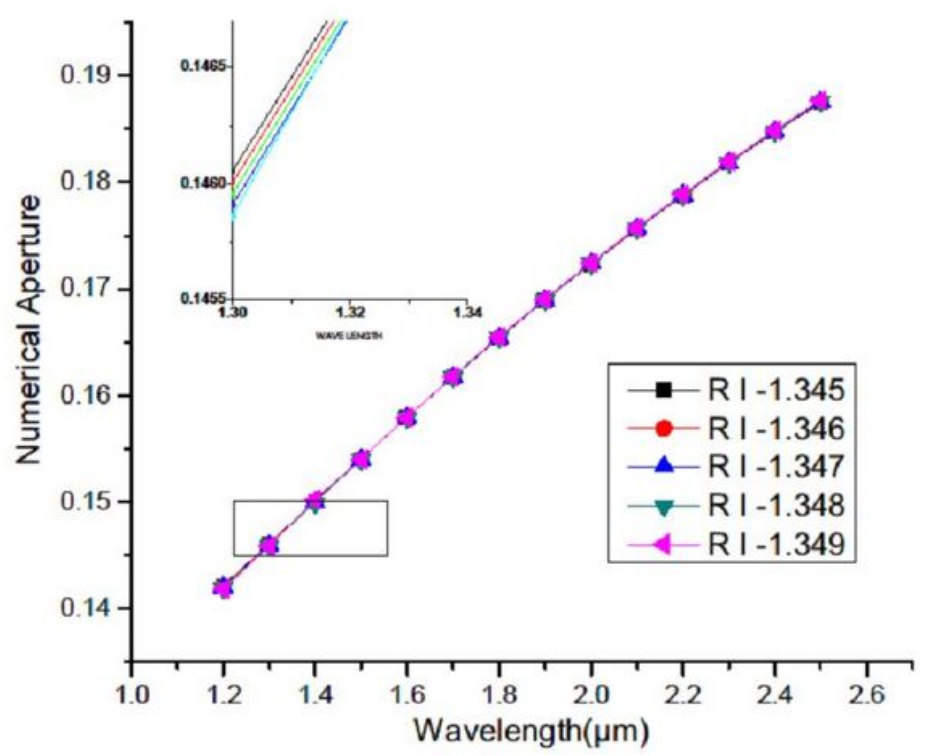

(b)

\section{Figure 9}

The variations of NA response with wavelength changing for the presented structure in both (a) XPolarization and (b)Y-Polarization 